TITLE:

\title{
Coseismic dehydration of serpentinite: Evidence from high- velocity friction experiments
}

\author{
$\operatorname{AUTHOR}(S):$ \\ Lin, Aiming; Takano, Soichiro; Hirono, Tetsuro; \\ Kanagawa, Kyuichi
}

\section{CITATION:}

Lin, Aiming ...[et al]. Coseismic dehydration of serpentinite: Evidence from high-velocity friction experiments. Chemical Geology 2013, 344: 50-62

\section{ISSUE DATE:}

2013-04-19

URL:

http://hdl.handle.net/2433/179481

\section{RIGHT:}

(c) 2012 Published by Elsevier B.V.; この論文は出版社版でありません。 引用の際には出版社版をご確認ご利用ください。; This is not the published version. Please cite only the published version. 
16

17 *Corresponding author:

18 Department of Geophysics

19 Graduate School of Science

20 Kyoto University

21 Kyoto 606-8502, Japan

22 Tel \& Fax: 81-76-753-394

23 E-mail: slin@kugi.kyoto-u.ac.jp

\title{
Coseismic dehydration of serpentinite: Evidence from
}

\section{high-velocity friction experiments}

\author{
Aiming Lin ${ }^{1}$, Soichiro Takano ${ }^{2}$, Tetsuro Hirono ${ }^{3}$, Kyuichi Kanagawa $^{4}$
}

${ }^{1}$ Department of Geophysics, Graduate School of Science, Kyoto University, Kyoto 606-8502, Japan

${ }^{2}$ Institute of Geosciences, Faculty of Science, Shizuoka University Shizuoka 422-8529, Japan ${ }^{3}$ Department of Earth and Space Science, Graduate School of Science, Osaka University, Toyonaka 500-0043, Japan ${ }^{4}$ Department of Earth Sciences, Chiba University, Chiba, Japan 24 


\section{ABSTRACT}

High-velocity friction (HVF) experiments on serpentinite under conditions equivalent

27 to large amounts of earthquake slip produced large volumes of water vapor derived from

28 the frictional-heating-induced dehydration of serpentinite. Fourier Transform Infrared (FTIR) and thermogravimetry (TG)-Differential Scanning Calorimetry (DSC) microspectroscopic analyses show that the water in the slip zone and its bounding zones was released due to dehydration during the HVF experiments. Our experimental results demonstrate that (i) the run product consists of $\sim 10 \mathrm{wt} . \%$ molten materials with abundant vesicles and $~ 90 \mathrm{wt} . \%$ fine-grained clasts; (ii) both serpentine and olivine minerals were melted during high-velocity slip $(1.1-1.3 \mathrm{~m} / \mathrm{s})$; (iii) rapid serpentine dehydration occurred in a zone of up to $\sim 3 \mathrm{~mm}$ wide, including the slip zone and its bounding zones, accompanying frictional melting during high-velocity slip; and (iv) no distinct dehydration or frictional melting occurred during low-velocity $\operatorname{slip}(<0.4 \mathrm{~m} / \mathrm{s})$. These findings show that dehydration reactions of serpentine can be caused by frictional heating that accompanies frictional melting in the slip zone, and by the rapid diffusion of frictional heat from the main slip zone to a wide zone bounded by the coseismic slip plane during seismic faulting. The present results reveal that the thermal pressurization caused by the dehydration of serpentine and frictional melting is a main mechanism that may lead to the dynamic weakening of seismogenic faults, thereby facilitating seismic

44 slip during large earthquakes in subduction zones and along intracontinental faults that contain abundant hydrous minerals.

47 Keywords: dehydration, serpentinite, high-velocity slip, fault strength, dynamic 
weakening of seismogenic fault, thermal pressurization

\section{Introduction}

51

Thermal pressurization has been proposed as a major mechanism of lowering the

53 dynamic strength of faults during earthquake slip [e.g., Sibson, 1973; Lachenbruch,

54 1980; Andrews, 2002; Wibberley and Shimamoto, 2005]. A commonly invoked

mechanism of thermal pressurization in this regard is a reduction in effective normal

stress induced by the sudden increase in pore pressure that arises from the release of

fluid via dehydration reactions [e.g., Meade and Jeanloz, 1991; Tibi et al., 2002]. In

recent years, many experimental studies have suggested that thermal pressurization may

result from mineral decomposition, such as the dehydration of serpentine or kaolinite

60 [e.g., Hirose and Bystricky, 2007; Brantut et al., 2008; Viti and Hirose, 2010; Kohli et

al., 2011], the decarbonation of calcite or siderite [Han et al., 2007, 2010], and the dehydration of gypsum [Brantut et al., 2011]. Observations of natural seismogenic fault cores that contain fault gouges also support the supposition that dehydration reactions occur during seismic faulting [e.g., Famin et al., 2008; Hamada et al., 2009, 2011].

Francis, 1981; Moore and Rymer, 2007] and with seismogenic faults within subduction zones [Ulmer and Trommsdorff, 1995]; indeed, the presence of serpentine minerals is considered to facilitate creep along the San Andreas Fault [Moore and Rymer, 2007], thereby explaining its low fault strength [Wibberley, 2007]. In numerical modeling, heat diffusion is considered an important coupling factor of thermal pressurization, which 
71 occurs normal to the slip zone [Brantut et al., 2010]. Should serpentine dehydration

72 occur due to frictional heating along seismogenic faults and should heat diffusion occur

73 within a wide dehydration reaction zone bounded by the slip zone during earthquake slip,

74 it is likely that a considerable volume of water would be released from serpentine-rich

75 slip zones and their bounding zones. Thus, it is proposed that a rapid dehydration

76 reaction involving serpentine would induce a sudden increase in fluid pressure that

77 would simultaneously act to reduce the effective normal stress and markedly weaken the

78 dynamic strength of seismogenic faults during seismic faulting.

79 To test this hypothesis, a low- to high-velocity rotary shear test apparatus [Lin, 2008]

80 was used to conduct uniaxial high-velocity friction (HVF) experiments under conditions

81 equivalent to large earthquake slip with various slip rates, using natural serpentinite

82 samples from Nagano Prefecture, Japan. This paper describes the results of these

83 experiments, which showed the instantaneous dehydration of serpentinite due to

84 frictional heating along the simulated fault and heat diffusion within a wide zone

85 bounded by the slip zone.

86

2. Experimental Procedure and Conditions

\subsection{Test Equipment}

90

91 All of the present experiments on frictional-heating-induced hydration of serpentine

92 were performed under dry conditions using a rotary-shear low- to high-velocity

93 frictional test machine installed at Shizuoka University, Japan (Fig. 1). This machine 
94 contains two testing devices: a uniaxial rotary-shear low- to high-velocity friction device

95 that lacks a hydraulic pressure vessel [as used by Lin and Shimamoto, 1998], and a

96 hydraulic friction apparatus with a controlling device for high pore-water pressure,

97 attached to the uniaxial rotary-shear low- to high-velocity friction device (Figs 1 and 2).

98 This device has a wide range of slip rates, from $<10 \mathrm{~cm} / \mathrm{yr}$ to $10 \mathrm{~m} / \mathrm{s}$, yielding

99 mechanical data such as torque, the frictional coefficient, amount of axial shortening,

100 normal stress and shear stress, pore-water pressure, frictional melt temperature, and

101 displacement. The test equipment can be used to apply normal stresses up to

102 approximately $100 \mathrm{MPa}$, close to the typical uniaxial strength of crystalline rocks,

103 provided that anvil-shaped specimens are used. In practical use, however, it is only

104 possible to apply normal stresses of $<15 \mathrm{MPa}$ because of the severe thermal fracturing

105 of unconfined specimens that occurs upon frictional heating.

106

107

\subsection{Experimental Conditions}

108

109 Serpentinite samples for the experiments, collected from Nagano Prefecture, central

110 Japan, were free of visible cracks and consisted of $\sim 65 \%$ antigorite and $\sim 35 \%$ olivine,

111 along with trace amounts of mafic minerals (Fig. 3).

112 Ten HVF experiments were performed at room temperature under dry conditions and

113 with equivalent slip rates [Shimamoto and Tsutsumi, 1994; Lin and Shimamoto, 1998]

114 of $1.10-1.31 \mathrm{~m} / \mathrm{s}$ and normal stresses of 2-9 MPa (Table 1). In such experiments, the

115 slip rate varies from the inner to outer circumferences of the sample, so we used the

116 equivalent slip rate (Veq), which is defined as Veq multiplied by the area of sliding 
117 equals the rate of frictional work. Assuming a constant frictional coefficient over the

118 sliding surface, Veq for a cylindrical specimen of diameter $r$ is given by

$$
\mathrm{Veq}=4 / 3 \pi \mathrm{rR}
$$

120 where $\mathrm{R}$ is the revolution rate of the motor [Shimamoto and Tsutsumi, 1994].

121 Low-velocity $(0.35-0.4 \mathrm{~m} / \mathrm{s})$ friction (LVF) experiments were conducted for comparison

122 with the results of the HVF experiments (Table 2). A pair of cylindrical specimens (25

$123 \mathrm{~mm}$ in diameter and $50 \mathrm{~mm}$ in length) was used in each experiment, with the circular

124 interface between the two specimens being set as the slip plane (Fig. 2). The sliding

125 surfaces were polished with 1500\# SiC powders. Because large normal stresses could

126 not be applied to the simulated fault due to the limitations of the experimental apparatus,

127 the HVF experiments were run over a period of $\sim 15-40 \mathrm{sec}$, corresponding to

128 displacements of 20-50 m. These displacements are comparable with those recorded

129 during large-magnitude earthquakes (e.g., maximum displacements of 15-30 m have

130 been reported for the $2001 \mathrm{M}_{\mathrm{w}} 7.8$ Kunlun earthquake [Lin et al., 2002], the $2004 \mathrm{M}_{\mathrm{w}}$

1319.0 Sumatra-Andaman earthquake [Subarya et al., 2006], and the $2011 \mathrm{M}_{\mathrm{w}} 9.0$ Offshore

132 Tohoku (Japan) earthquake [Yagi and Fukahata, 2011]). In contrast, the total

133 displacements over a period of $\sim 15-40 \mathrm{sec}$ in the LVF experiments were calculated to

134 be $5-15 \mathrm{~m}$. The frictional energy expended per unit area in the experiments under a slip

135 rate of $\sim 1 \mathrm{~m} / \mathrm{s}$ and a large displacement of up to $50 \mathrm{~m}$ is similar to that expended during

136 a medium- to large-magnitude crustal earthquake [O'Hara et al., 2006], at least in terms

137 of slip velocity and stress drop [Kanamori and Brodsky, 2004].

138 Serpentine dehydration phenomena were directly observed during the HVF

139 experiments $(1.10-1.31 \mathrm{~m} / \mathrm{s})$ through a transparent window cover on the experimental 
140 apparatus (Fig. 4). The simulated fault began to produce water vapor and dust within 0.2

141 sec of the initiation of fault motion (Fig. 4a). Water vapor, accompanied by sparks and

142 red melt material, was sprayed out from the slip zone, with some instantaneously

143 cooling to water droplets $(0.1-5.0 \mathrm{~mm}$ in diameter) on the transparent window cover

144 (Fig. 4b-d). The ejection of water vapor from the simulated fault continued until the end

145 of each experiment, with the droplets on the window cover forming a band of 3-7 mm

146 in width (Fig. 4b-d). In contrast, such water vapor and water droplets were not observed

147 during the LVF experiments.

\section{Results}

150

\subsection{Microstructures of Run Products}

152

153 The slip zones that formed during the experiments ranged in width from 0.1 to 2.0

$154 \mathrm{~mm}$, consisting of numerous fractured fragments of olivine within a very fine-grained

155 matrix that was too fine to enable the identification of minerals (Figs 5 and 6), even by

156 powder X-ray diffraction analysis. The olivine crystals abutting the slip zone were

157 generally fractured, with numerous cracks infilled by molten run products containing

158 fine-grained clasts, forming complex network veins branching from the main slip zone

159 (Fig. 5a). These veins resemble natural pseudotachylyte veins in their geometry and 160 morphology [Lin, 2008]. In contrast, the antigorite crystals that abut the slip zone were

161 mainly decomposed, without distinct cracks or fibrous textures as those observed in the

162 host rock far from the slip zone (Figs 5 and $6 a-c)$. These textural features indicate that 
163 the serpentine crystals were decomposed in a narrow zone of $<3 \mathrm{~mm}$ width, developed

164 each side of the slip zone, within which the serpentine was subjected to dehydration

165 reactions during the HVF experiments (see below for details).

166 Some molten run products were extruded from the simulated fault after $0.5 \mathrm{sec}$ of the 167 onset of slip, occurring as irregular branch-like forms of $<2 \mathrm{~mm}$ in diameter and up to 3

$168 \mathrm{~cm}$ in length, showing flow structure and with a vitreous luster similar to that of fresh

169 lava (Fig. 7a). Molten material that includes numerous fine-grained clasts is generally

170 heterogeneous in texture under the microscope, showing flow structure and containing

171 numerous spherical to elliptical vesicles ranging in diameter from sub-micron size to 0.5

$172 \mathrm{~mm}$ (Figs 6d and 7b). Such vesicular structures are considered to form via the extrusion

173 of gas (water vapor) from a melt during frictional melting, as reported previously in both

174 natural pseudotachylyte [e.g., Maddock et al., 1987; Lin, 1994, 2008; Magloughlin,

175 2011] and experimentally generated pseudotachylyte [Lin and Shimamoto, 1998]. These

176 structural features observed in the present experiments indicate that molten material

177 formed and water vapor was released from the slip zone during the HVF experiments

178 (Fig. 4).

179 The vesicles and flow structures are observed in narrow zones of $<3 \mathrm{~mm}$ wide

180 bounded by antigorite crystals on each side of the slip zone (Figs 5a and 6a-c). The

181 fibrous textures of antigorite crystals observed in the starting serpentine samples are not

182 recognized in the dehydration zones that abut the slip zone (Figs $5 \mathrm{~b}$ and $6 \mathrm{a}-\mathrm{c}$ ).

\section{3.2. Powder X-ray Diffraction Analysis}


186 Two types of run products were analyzed by powder X-ray diffraction method: one is

187 the molten material remained in the slip zone (HVF R001), and another is the molten

188 material of run product extruded from the slip zone during the HVF experiment (HVF

189 R012). For comparison with the run products, the host serpentinite sample and olivine

190 mineral sample were also analyzed. Powder X-ray diffraction analyses reveal that the

191 diffraction peaks of antigorite are absent from the spectra of the run products, even

192 though antigorite made up $\sim 65 \%$ of the starting samples (Fig. 8). The integrated

193 intensities of olivine peaks in the spectra for run materials (Fig. 8c, d) are slightly

194 stronger than those for the serpentinite sample (Fig. 8a). The diffraction spectra of both

195 types of run products contain a distinctive, broad band ranging from $2 \theta$ values of $12^{\circ}$ to

$19642^{\circ}$, comparable with that for a standard sample containing 5-10 wt.\% glass (Fig. 8d-f).

197 These diffraction patterns are also comparable with the XRD spectra of standard

198 samples analyzed for the quantitative calibration of glassy materials contained in the

199 HVF experimentally generated pseudotachylyte, as reported by Lin and Shimamoto

200 (1998). This finding indicates that up to $10 \mathrm{wt} . \%$ glass or amorphous material formed in

201 the run products that were extruded and remained in the slip zone during the present

202 experiments, as observed under optical and electron microscopes (Figs 5 and 6).

203

204 3.3. Chemical Compositions

205

206

The bulk chemical composition of serpentinite samples used in the frictional

207 experiments was analyzed by X-ray fluorescence (XRF) (sample Host1 in Table 2). For

208 comparison with the run products, the chemical composition of serpentine and olivine 
209 minerals in samples of host rock (samples HS1-HS5 and HO1-2 in Table 2) was

210 measured using an electron-probe microanalyzer (EPMA, JXA733). The chemical

211 compositions of run products in the slip zone and in the dehydration zones (Fig. 5) were

212 measured from a thin section oriented perpendicular to the slip zone, as shown in Fig. 3c

213 (Tables 3-4).

214 The molten materials derived from the slip zone are generally heterogeneous in 215 chemical composition (Fig. 9, Table 3), which differs from the bulk composition of the 216 host rock, and from that of serpentine and olivine minerals contained in the host rock, 217 respectively (Fig. 9, Table 2). The serpentine minerals in the dehydration zones

218 (samples Dh1-Dh8 in Table 4) have a similar composition with that of serpentine 219 minerals in the host rock with the sum of elements of 2.82-2.84 (Fig. 9, samples 220 HS1-HS6, in Table 2). The variation diagrams of major oxides show a characteristic 221 change in $\mathrm{SiO}_{2}, \mathrm{MgO}, \mathrm{FeO}, \mathrm{CaO}$ and $\mathrm{Al}_{2} \mathrm{O}_{3}$ components in the run products (Fig. 9).

222 Comparing with the dehydration zones, the molten materials in the slip zone have lower $223 \mathrm{SiO}_{2}$ and $\mathrm{Al}_{2} \mathrm{O}_{3}$ components and higher $\mathrm{FeO}$ component similar to that of olivine 224 minerals contained in the host rock (Fig. 9). The slip zone has a large variation range in $225 \mathrm{CaO}$ and $\mathrm{FeO}$ components which are generally higher than that of serpentine minerals 226 contained in the host serpentinite. There is also a large variation range in $\mathrm{MgO}$ 227 component of the molten materials. In contrast, there is a small variation range in $\mathrm{MgO}$ 228 component in serpentine minerals contained in the host serpentinite and dehydration zone (Fig. 9). The variations of chemical composition in the molten materials may be

230 caused by friction melting of serpentine and olivine minerals, in which molten materials 231 were not completely mixed and contaminated. 
The analytical totals of the molten materials in the slip zone and serpentine minerals

233 that abut the slip zone are up to $>97.6-99.6 \mathrm{wt} . \%$ (Tables 3-4), higher than that of

234 serpentine minerals in the host rock (samples HS1-HS6 in Table 2). These high total

235 amounts can be interpreted as a result of water release from the slip zone and bounding

236 zones due to the dehydration of serpentine minerals (see below for details).

237

238

\subsection{Frictional Coefficient and Shortening Amount}

239

The frictional coefficient $\mu$ showed an immediate increase to 0.56 at the onset of slip,

241 within the first $0.1 \mathrm{sec}$ of the experiments, but just as quickly dropped to a steady-state

242 value of 0.23 prior to an elapsed time of $0.2 \mathrm{sec}$ during the HVF experiments (Fig.

$24310 \mathrm{a}-\mathrm{b})$. This pronounced peak in friction accompanied the outspray of water vapor and

244 axial shortening of the sample within the first $0.2 \mathrm{sec}$ of each run. In contrast to the HVF

245 experiments, during the LVF experiments the frictional coefficient $\mu$ increased to 0.57

246 within a 2.5 -sec period after $1 \mathrm{sec}$ of the onset of slip, and gradually dropped to a

247 steady-state value of 0.28 prior to an elapsed time of $\sim 20 \mathrm{sec}$, without distinct axial

248 shortening in the first $60 \mathrm{sec}$ (Fig. 10c-d). This result indicates that slip weakening

249 occurred over a shorter period during the HVF experiments compared with the LVF

250 experiments.

251 During the HVF experiment, axial shortening occurred in the first $0.5 \mathrm{sec}$, and the

252 shortening amount decreased slightly from 0.025 to $0.02 \mathrm{~mm}$ over a period of $4.5 \mathrm{sec}$,

253 which corresponds to the onset of extrusion of molten run materials from the slip zone

254 (Fig. 10b). Significant shortening occurred continuously from $5 \mathrm{sec}$ after the onset of 
255 high-velocity slip (Fig. 10a), which corresponds to the period of extrusion of large

256 amount of molten run products from the slip zone (Fig. 4). In contrast, during the LVF

257 experiments, shortening occurred after $61 \mathrm{sec}$ had passed since the initiation of slip (Fig.

$258 \quad 10 \mathrm{c}-\mathrm{d})$.

259

260

\subsection{FTIR and TG-DSC Analyses}

261

262

To quantitatively analyze the water contents of the starting rock sample and the run products, we performed Fourier transform infrared (FTIR) and thermogravimetry

264 (TG)-differential scanning calorimetry (DSC) spectroscopic analyses using Jasco

265 FT/IR-300E and Netzsch STA 449C Jupiter apparatuses, respectively.

The run products of three HVF experiments (slip rate of $1.10 \mathrm{~m} / \mathrm{s}$ and normal stresses of 2, 5, and $9 \mathrm{MPa}$, respectively) were selected for FTIR analysis, which was performed 268 along profiles across the slip zone in thin sections of $\sim 0.25 \mathrm{~mm}$ thick. In the FTIR spectra, absorption bands are observed at the $\mathrm{OH}$ stretching region $\left(3500-3700 \mathrm{~cm}^{-1}\right)$ in

270 the host serpentine sample but not in the slip zone ('run product' in Fig. 11). This result

271 indicates that little water $(\mathrm{OH})$ remained in the slip zone. The water contents were

272 calculated using $\mathrm{OH}$ peaks at $3500-3700 \mathrm{~cm}^{-1}$ based on the method proposed by Beran

273 and Libowitzky [2006]. The calculated water contents are shown in Fig. 12.

274 The FTIR analyses show that no water occurs in the slip zone or in the adjacent 275 dehydration zones, and the water content ranges from 0.5 to $15 \mathrm{wt} . \%$ in the host rocks

276 (Fig. 12). These results indicate that all of the water in the slip zone and adjacent 277 dehydration zones (see Fig. 11) was released during the HVF experiments. 

MH001) experiments performed under normal stresses of 2.4-2.5 MPa, were powdered

280 for TG-DSC analysis. For comparison, one sample of host rock was also analyzed.

281 Approximately $30 \mathrm{mg}$ of sample was placed in a covered $\mathrm{Pt}_{90} \mathrm{Rh}_{10}$ crucible and heated from $25^{\circ} \mathrm{C}$ to $1050^{\circ} \mathrm{C}$ at a rate of $10^{\circ} \mathrm{C} \mathrm{min}^{-1}$ under a flow of nitrogen gas $\left(50 \mathrm{ml} \mathrm{min}^{-1}\right)$.

The DSC-TG spectra of the host rock sample reveal (i) a weight loss after heating of 2846.9 wt.\%, as determined by TG (Fig. 13a); and (ii) the heat flux during heating showed an endothermic peak at $550-700^{\circ} \mathrm{C}$ and an exothermic peak at $800-850^{\circ} \mathrm{C}$ (Fig. 13b). The first peak was accompanied by a weight loss, indicating that it corresponds to a 287 dehydroxylation reaction. The second peak was not accompanied by a weight loss, and 288 its relation to the reactions is currently unknown. The host sample was heated a second 289 time, from $25^{\circ} \mathrm{C}$ to $1050^{\circ} \mathrm{C}$, showing no weight loss and no endothermic peak, 290 confirming that the dehydroxylation was completed during the first heating. The EPMA analyses indicate marked differences in the analytical totals among the serpentine minerals of the host rock (Table 2), the molten material remaining in the slip zone

293 (Table 3), and the dehydration zones (Table 4). The totals for the molten materials and 294 dehydration zones that abut the slip zone are up to $97-99.5 \mathrm{wt} . \%$, about 9-11 wt.\% higher than that of the serpentine minerals of the host rock. Considering the presence of $296 \sim 35 \%$ olivine in the host rock sample, the differential amounts of $9-11 \mathrm{wt} . \%$ are 297 comparable to the weight loss of $6.9 \mathrm{wt} . \%$ in the run products, including molten 298 materials and fine-grained clasts of the host rock, as determined by TG (Fig. 13a). 299 Accordingly, the difference in analytical total reflects the release of water from the 300 molten materials and from serpentine minerals that abut the slip zone, due to the 
301

302

303

304

305

306

307

308

309

310

311

312

313

314

315

316

317

dehydration of serpentine minerals.

Figure 13 shows the TG -DSC spectra of four run products, revealing that the total weight losses of water are 0.0 wt.\% for samples No. 1 and No. 3, 7.3 wt.\% for MH001, and 4.3 wt.\% for MH002 (Fig. 14a). Samples No. 1 and No. 3 show no significant endothermic peak at around $550-700^{\circ} \mathrm{C}$ (Fig. 14b), indicating that the dehydroxylation reaction was completed in the HVF samples. In contrast, MH001 and MH002 show a weight loss and an endothermic peak at around $550-700^{\circ} \mathrm{C}$ (Fig. 14b), similarly to the host rock (Fig. 13b). This result suggests that the dehydroxylation reaction was not completed during the LVF friction experiment at a low velocity of $0.35 \mathrm{~m} / \mathrm{s}$.

\section{Discussion and Conclusions}

\subsection{Coseismic Melting and Dehydration Reaction}

The ejection of water vapor and the generation of vesicles within run products during the HVF experiments provide conclusive proof that water was released from the slip zone. The flow structures, the vitreous luster of run products (similarly to that of fresh lava), and X-ray diffraction patterns indicate the coexistence of abundant fluid derived from serpentine and frictional melt resulting from frictional heating in the slip zone. The absence of antigorite crystals in the X-ray diffraction spectra of run products can be interpreted as a result that antigorite crystals were completely broken down and/or melted by friction heating.

As shown in Fig. 9, the molten materials have lower $\mathrm{SiO}_{2}$ and $\mathrm{Al}_{2} \mathrm{O}_{3}$ components and 
324 higher $\mathrm{FeO}$ component similar to that of olivine mineral contained in the host rock than

325 that of serpentine mineral in the dehydration zone, and higher $\mathrm{CaO}$ and $\mathrm{FeO}$ components

326 than that of serpentine contained in the host serpentinite. The FeO component of the

327 molten materials is about $5 \sim 7 \mathrm{wt} \%$ higher than that of serpentine minerals contained in

328 the host serpentinite and the dehydration zones, which is similar to that of olivine

329 mineral contained in the host rock (Fig. 9). Furthermore, $\mathrm{MgO}$ and $\mathrm{Al}_{2} \mathrm{O}_{3}$ components of

330 the molten materials are locally similar to that of olivine mineral, higher that of the host

331 serpentine minerals contained in the host serpentinite and the dehydration zones (Fig. 9).

332 These textural and petrologic features including the chemical compositions of molten

333 materials reveal that the not only the serpentine but also the olivine minerals were

334 melted by friction heating, and that a high temperature reached the bounding zones of

335 the slip zone at which serpentine was involved in a dehydration reaction. Previous

336 studies show that the high-velocity friction melting occurs in a chemically

337 non-equilibrium process (Lin and Shimamoto, 1998; Lin, 2008) and that the melting or

338 breakdown of serpentine mineral occurs at temperature of $400 \sim 600{ }^{\circ} \mathrm{C}$ [Spray, 1992].

339 Thus, the serpentine and olivine minerals are considered to be melted at temperature of

$340 \geq$ melting points of these minerals. Based on the melting point $\left(\sim 1890^{\circ} \mathrm{C}\right)$ of olivine

341 [Spray, 1992], it is estimated that the temperature in the slip zone reached at least up to

$3421890^{\circ} \mathrm{C}$ during the HVF experiments.

343 Previous studies indicate that the dehydration of serpentine occurs at temperature of

$344 \geq 500^{\circ} \mathrm{C}$ [Ulmer and Trommsdorff, 1995; Viti, 2010] to $856^{\circ} \mathrm{C}$ [Lange and Ahrens,

345 1982]. In previous HVF experiments using marble samples, direct thermometer-based

346 measurements of temperature indicate that the slip-zone temperature can reach 
$347600-900^{\circ} \mathrm{C}$ during the first $0.1 \mathrm{sec}$ of the experiment at a slip rate of $1.17 \mathrm{~m} / \mathrm{s}$ [Han et al.,

348 2007]. TG, DTG and differential thermal analyzer (DTA) analyses show that serpentine

349 dehydration takes place between 550 and $800^{\circ} \mathrm{C}$ [Viti, 2010]. Calculation results for an

350 HVF experiment on serpentinite at a slip rate of $1.1 \mathrm{~m} / \mathrm{s}$ reveal that the flash temperature

351 can rise by $\sim 1250^{\circ} \mathrm{C}$ over a period of $<0.1 \mathrm{sec}$ [Hirose and Bystricky, 2007] and that the

352 temperature can reach $550-1100^{\circ} \mathrm{C}$ within a narrow slip zone $(<3 \mathrm{~mm}$ wide $)$ over a

353 period of 2-3 sec [Fukuchi and Imai, 2001]. Furthermore, seismic data reveal that if the

354 shear energy is constrained within $1 \mathrm{~cm}$ of the slip plane during seismic slip, the

355 temperature can readily increase to $100-1000^{\circ} \mathrm{C}$ during a medium- to large-magnitude

356 earthquake [Kanamori and Brodsky, 2004]. Thus, the temperature up to $1890^{\circ} \mathrm{C}$ in the

357 present HVF experiments as documented above, within a dehydration zone of $<2 \mathrm{~mm}$ in

358 width (Fig. 12) and at slip rates of $1.10-1.31 \mathrm{~m} / \mathrm{s}$, is sufficient to induce the dehydration

359 of serpentine.

360 The breakdown of serpentine to olivine + talc + water and the breakdown of talc to

enstatite + quartz + water at 1 bar follow a second-order rate law [Bose and Ganguly,

362 1994]. The breakdown of antigorite in the present experiments is indicated by the

363 consumption of antigorite and increased integrated intensities of olivine in the X-ray

364 diffraction spectra for the run products, although talc could not be identified from the

365 spectra. Direct observations made during the present experiments also demonstrate that

366 serpentine dehydration reaction occurred within $0.2 \mathrm{sec}$ of the onset of slip. Furthermore,

367 the antigorite crystals observed in the dehydration zones that abut the slip zone show

368 textural features indicative of decomposition, without the distinct cracks and fibrous

369 texture observed in the starting sample of host rock (Figs 5 and $6 \mathrm{a}-\mathrm{c}$ ). This finding 
370 demonstrates that the serpentine dehydration reaction that occurred in a wide zone

371 involving the slip zone was caused mainly by the diffusion of frictional heat from the

372 slip zone. Our results support the idea that the diffusion of frictional heat is a major

373 coupling factor of thermal pressurization caused by the dehydration of serpentine within

374 seismogenic fault zone [Brantut et al., 2010].

375

376

\subsection{Mechanism of Dynamic Weakening}

377

The dynamic weakening of faults during earthquakes is considered to result from

several mechanisms, including friction melting [Spray, 1993; Hirose and Shimamoto, 2005; Di Toro et al., 2006, 2011], the presence of S-C cataclasites [Lin, 1999, 2008], the formation of fault gouge [e.g., Rice, 2006; Mizoguchi et al., 2007], thermal pressurization [e.g., Lachenbruch and Sass, 1980; Wibberley and Shimamoto, 2005], dehydration reactions involving water-rich minerals such as serpentine and kaolinite [e.g., Hirose and Bystricky, 2007; Brantut et al., 2008; Viti and Hirose, 2010; Kohli et al., 2011] as well as fault gouges present in seismogenic fault zones [e.g., Famin et al., 2008; Hamada et al., 2009, 2011], thermal decomposition [Han et al., 2007], and the dehydroxylation of mica minerals [Hirono and Tanikawa, 2011]. Each of these mechanisms is closely linked to frictional heating generated upon the fault plane during

389 seismic slip. The frictional melt generated in the slip zone also plays an important role 390 in lubricating the slip plane, thereby facilitating further slip along seismogenic faults

391 during large earthquakes [e.g., Di Toro et al., 2006, 2011]. Although dynamic fault 392 strength during frictional melting is commonly considered to be controlled by the 
393 development of a molten layer and by the viscosity of this layer [Spray, 1993; Hirose

394 and Shimamoto, 2005], the serpentinite dehydration may also be a main mechanism

395 resulting in a dramatic increase in pore pressure that may lead to the dynamic weakening

396 of seismogenic faults. The outspray of water vapor within the first $0.2 \mathrm{sec}$ of each run as

397 observed during the HVF experiments indicates that the dehydration of serpentine

398 occurred in the first $0.2 \mathrm{sec}$. The fact that molten materials were squeezed out after 0.5

399 sec after the onset of the slip from the slip zone as observed during the experiments

400 reveals that a molten layer was produced in the same time as the water vapor within the

401 slip zone during the first $0.5 \mathrm{sec}$. These findings indicate that both water vapor and

402 molten material were co-existed in the slip zone in the first $0.5 \mathrm{sec}$ of the run. It may be

403 difficult to produce sufficient fault gouge material to affect the fault strength over a

404 short duration of $0.2 \mathrm{sec}$ because of small amount of generated slip. Accordingly, the

405 dramatic decrease in the frictional coefficient from 0.56 to 0.25 in the first $0.2 \mathrm{sec}$ after

406 the onset of slip (Fig. 10a-b) can be interpreted as a result of thermal pressurization

407 caused by the dehydration of serpentine that accompanies frictional melting during the

408 HVF experiments. In contrast, similar weakening was observed in the LVF experiments,

409 in which the frictional coefficient decreased from 0.55 to 0.25 , but this took $\sim 10 \mathrm{sec}$

410 after the onset of run (Fig. 10c-d). This may be interpreted as that enough amount of

411 fine-grained material (fault gouge) formed in the slip zone which weakened the fault

412 strength as proposed by previous studies [Rice, 2006; Mizoguchi et al., 2007].

413 In the present study, it is considered that the main weakening mechanism of the

414 simulated faults under conditions equivalent to large earthquake slip was the thermal

415 pressurization caused by serpentine dehydration associated with frictional heating and 
416 melting, resulting in the excess saturation pressure of water vapor and fluid including

417 melt in the slip zone. Previous studies show that frictional heating would cause the fluid

418 in the fault gouge to expand in volume much more than would be the solid cage [e.g.,

419 Sibson, 1973, Lachenbruch and Sass, 1980]. Thus, shear-induced dilatancy of the gouge

420 overwhelms the thermal expansion effect and a pressure increased must be induced in

421 the pore pressure [Rice and Cocco, 2007]. The saturation pressure of water vapor is

422 known to vary with the temperature of the vapor [Kaye and Laby, 1986]: when confined

423 water is heated, the saturation pressure of water vapor $(\mathrm{P})$ shows a rapid increase.

424 Assuming ideal gas (water vapor) behavior, $\mathrm{P}=\mathrm{nRT} / \mathrm{V}$, where $\mathrm{n}$ is the number of moles,

$425 \mathrm{R}$ is the water vapor constant, $\mathrm{T}$ is absolute temperature $(\mathrm{K})$, and $\mathrm{V}$ is the volume of

426 water vapor. From room temperature $\left(20^{\circ} \mathrm{C}\right)$ to $360^{\circ} \mathrm{C}, \mathrm{P}$ increases by three orders of

427 magnitude, from $\sim 10^{-2}$ to $\sim 20 \mathrm{MPa}$ [Kaye and Laby, 1986]. Theoretically, under the

428 pressure-temperature conditions of seismogenic depths, the thermal expansivity of

429 water is on the order of $10^{-3} /{ }^{\circ} \mathrm{C}$, meaning that the increase in fluid pressure at the depths

430 of hypocenters would be on the order of $1 \mathrm{MPa} /{ }^{\circ} \mathrm{C}$ [Lachenbruch and Sass, 1980 ;

431 Kanamori and Brodsky, 2004]. Thus, the corresponding pressure of water vapor and

432 fluid would be $>20 \mathrm{MPa}$ in a simulated fault zone under conditions equivalent to large

433 earthquake slip, comparable to the stress drop that occurs during large earthquakes

434 [O'Hara et al., 2006]. In the present HVF experiments, the decrease in the average

435 shortening amount in the first $5 \mathrm{sec}$ after the onset of slip can be interpreted as a result

436 of pore pressure increase due to the thermal pressurization that accompanies frictional

437 melting within the slip zone. The subsequent increase in the average shortening amount

438 could reflect the extrusion of run products (including vapor, melt, and fine-grained 
materials) from the slip zone, as shown in Fig. 4.

440 Our results support the idea that the thermal pressurization of fluid released by the

441 dehydration of serpentine and friction melt plays an important role in the dynamic

442 weakening of faults during seismic slip within seismogenic fault zones.

\subsection{Tectonic Implications}

The present experimental results have significant implications for subduction zone earthquakes and transform faults such as the San Andreas Fault. Seismogenic faults within a subduction zone are generally associated with a mantle wedge composed of serpentinites that contain $\sim 13$ wt.\% $\mathrm{H}_{2} \mathrm{O}$ [Ulmer and Trommsdorff, 1995]. Hydrous antigorite may play an important role in the transport of water into the earth when it enters a subduction zone. The present results show that the frictional heat generated upon a seismogenic slip plane under conditions of large earthquake slip can lead to melting in a seismic slip zone and the dehydration of serpentinite within a wide dehydration reaction zone (comprising the main slip zone and bounding zones) due to the diffusion of frictional heat from the slip plane, thereby increasing the pore pressure due to the thermal expansivity of fluid and water vapor. Furthermore, the frictional melt

457 generated in the slip zone also plays an important role in lubricating the slip plane,

458 facilitating further slip along seismogenic faults during large earthquakes (Di Toro et al., 459 2011). Accordingly, our experiment results confirm that the serpentine dehydration that 460 accompanies frictional melting results in a sudden increase in pore pressure, which in 461 turn may lead to a reduction in the effective normal stress across the fault, in turn 
462 resulting in a marked reduction in the dynamic fault strength, thereby enabling further

463 slip along the fault in a subduction zone.

464 This sequence of events might also influence the physics of earthquake processes

465 within subduction zones, explaining the large seismic slip of $>15-50 \mathrm{~m}$ generated by

466 huge subduction-zone earthquakes such as the $2004 \mathrm{M}_{\mathrm{w}} 9.4$ Sumatra-Andaman

467 earthquake [Subarya et al., 2006] and the $2011 \mathrm{M}_{\mathrm{w}} 9.1$ Tohoku Japan earthquake [Yagi

468 and Fukahata, 2011]. In addition, if the large volumes of fluid released by the

469 dehydration of serpentinites during huge earthquakes are concentrated upon and migrate

470 along pre-existing fault zones to neighboring fault segments, such a sudden increase in

471 fluid pressure would promote further brittle failure in barrier areas of seismogenic faults

472 and in neighboring fault segments. The present results indicate that the dynamic

473 parameters of seismogenic faults are strongly affected by serpentine dehydration during

474 large earthquakes within subduction zones and along intracontinental faults that contain 475 abundant hydrous minerals.

476

477 Acknowledgments

478

479 We are grateful to Prof. T. Shimamoto for designing the rotary-shear low- to

480 high-velocity test machine. This work was supported by a Grand-in-Aid for Scientific

481 Research (Science Project No. 23253002 for A. Lin) from the Ministry of Education,

482 Culture, Sports, Science and Technology of Japan. 


\section{References}

485

Andrews, D. J., 2002. A fault constitutive relation accounting for thermal pressurization of pore fluid. J. Geophys. Res. 107, B001942, doi:10.1029/2002J.

Beran, A., Libowitzky, E., 2006. Water in natural mantle minerals II: olivine, garnet and accessory minerals. Reviews in Mineralogy and Geochemistry, 62, 169-191.

Bose, K., Ganguly, J., 1994. Thermogravimetric study of dehydration kinetics of talc. Am. Mineral. 79, 692-699.

Brantut, N., Schubnel, A., Rouzaud, J.-N., Brunet, F., Shimamoto , T., 2008. High velocity frictional properties of a clay-bearing fault gouge and implications for earthquake mechanics. J. Geophys. Res. 113, B10401, doi:10.1029/2007JB005551.

Brantut N., Schubnel, A., Corvisier, J., Sarout, J., 2010. Thermochemical pressurization of faults during coseismic slip. J. Geophys. Res. 115, B05314, doi:10.1029/2009JB006533.

Brantut, N., Han, R., Shimamoto, T., Findling, N., Schubnel, A., 2011. Fast slip with inhibited temperature rise due to mineral dehydration: Evidence from experiments on gypsum. Geology 39, 59-62.

501 Christensen, N. J., 1972. The abundance of serpentinites in the oceanic crust. J. Geophys. Res. 80, 709-719.

503 Di Toro, G., Goldsby, D. L., Tullis, T. E., 2006. Friction falls towards zero in quartz $504 \quad$ rock as slip velocity approaches seismic rates. Nature 427, 436-439.

505 Di Toro, G., Han, R., Hirose, T., De Paola, N., Nielsen, S., Mizoguchi, K., Ferri, F., 506 Cocco, M., Shimamoto, T., 2011. Fault lubrication during earthquakes, Nature, 471, 
494-498.

508 Famin, V., Nakashima, S., Boullier, A.-M., Fujimoto, K., Hirono, T., 2008. Earthquake 509 produce carbon dioxide in crustal faults. Earth and Planetary Sci. Lett. 265, $487-497$.

511 Francis, T. J. G., 1981. Serpentinization faults and their role in the tectonics of slow spreading ridges. J. Geophys. Res. 86, 11616-11622.

513 Fukuchi, T., Imai, N., 2001. ESR and ICP analyses of the DPRI $500 \mathrm{~m}$ drill core samples penetrating through the Nojima Fault, Japan. Island Arc 10, 465- 478.

515 Goldsby, D.L., Tullis, T., 2011. Flash heating leads to low frictional strength of crustal rocks at earthquake slip rates. Science 334, 216-218.

517 Hamada, Y., Hirono, T., Tanikawa, W., Soh, W., Song, S., 2009. Energy taken up by co-seismic chemical reactions during a large earthquake: An example from the 1999 Taiwan Chi-Chi earthquake. Geophys. Res. Lett. 36, L06301, doi:10.1029/2008GL036772.

Hamada, Y., Hirono, T., Ishikawa, T., 2011. Coseismic frictional heating and fluid-rock interaction in a slip zone within a shallow accretionary prism and implications for earthquake slip behavior. J. Geophys. Res. 116, B01302, doi:10.1029/2010JB007730.

Han, R., Shimamoto, T., Hirose, T., Ree, J.-H., Ando J., 2007. Ultra-low friction of carbonate fault caused by thermal decomposition. Science 316, 878-881.

527 Han, R., T. Hirose, Shimamoto, T., 2010. Strong velocity weakening and powder 528 lubrication of simulated carbonate faults at seismic slip rates. J. Geophys. Res. 115, 529 B03412, doi:10.1029/2008JB006136. 
530 Hirono, T., Tanikawa, W., 2011. Implications of the thermal properties and kinetic parameters of dehydroxylation of mica minerals for fault weakening, frictional heating, and earthquake energetics. Earth and Planetary Sci. Lett. 307, 161-172.

533 Hirono, T., Fujimoto, K., Yokohama, K., Hamada, T., Tanikawa, W., Tadai, O.,

534 Mishima, T., Tanimizu, M., Lin, W., Soh, W., Song, S., 2008. Clay mineral

535 reactions caused by frictional heating during an earthquake: An example from the

$536 \quad$ Taiwan Chelungpu fault. Geophys. Res. Lett., 35, L16303,

537 doi:10.1029/2008GL034476.

538 Hirose, T., Shimamoto, T., 2005. Growth of molten zone as a mechanism of slip

539 weakening of simulated faults in gabbro during frictional melting. J. Geophys. Res.

$540 \quad 110$, B05202, doi:10.1029/2004JB003207.

541 Hirose, T., Bystricky, M., 2007. Extreme dynamic weakening of faults during

542 dehydration by coseismic shear heating. Geophys. Res. Lett. 34, L14311, $543 \quad$ doi:10.1029/2007GL030049.

544 Kanamori, H., Brodsky, E. E., 2004. The physics of earthquake, Rep. Prog. Phys. 67, $545 \quad 1429-2496$.

546 Kaye, G.W.C., Laby, T. H., 1986. Tables of physical and chemical constants. John $547 \quad$ Willey and Sons Inc., New York, 432p.

548 Kohli, A.H., Goldsby, D. L., Hirth, G., Tullis, T., 2011. Flash weakening of serpentinite 549 at near-seismic slip rates. J. Geophys. Res. 116, B03202, doi:10.1029/2010JB007833

551 Lachenbruch, A. H., and J. H. Sass (1980), Frictional heating, fluid pressure, and the 552 resistance to fluid motion. J. Geophys. Res., 85, 6185-6222. 
553 Lange, M. A., Ahrens, T. J., 1982. Impact induced dehydration of serpentine and the evolution of planetary atmospheres, J. Geophys. Res. 87, A451-A456.

Lin, A., 1994. Glassy pseudotachylyte veins from the Fuyun fault zone, northwest China. J. Struct. Geol. 16, 71-83.

Lin, A., 1999. S-C cataclasite in granitic rocks. Tectonophysics 304, 257-273.

558 Lin, A., 2002. Co-seismic strike-slip and rupture length produced by the Ms 8.1 Central $559 \quad$ Kunlun earthquake. Science 296, 2015-2017.

560 Lin, A., 2008. Fossil earthquakes: the formation and preservation of pseudotachylytes. Springer, Berlin, 348p.

Lin, A., Shimamoto, T., 1998. Selective melting processes as inferred from experimentally-generated pseudotachylytes,. J. Asian Earth Sci. 16, 533-545.

Maddock, R. H., Grocott, J., Van Nes, J., 1987. Vesicles, amygdales and similar structures in fault-generated pseudotachylytes. Lithos 20, 419-432.

Magloughlin, J. F., 2011. Bubble collapse structure: a microstructural record of fluids, bubble formation and collapse, and mineralization in pseudotachylyte. Journal of Geology 119, 351-371.

Meade, C., Jeanloz, R., 1991. Deep focus earthquake and recycling of water into the Earth' mantle. Science 252, 68-72.

Mizoguchi, K., Hirose, T. Shimamoto, T., Fukuyama, F., 2007. Reconstruction of seismic faulting by high-velocity friction experiments: An example of the 1995 Kobe earthquake. Geophys. Res. Lett. 34, L01308, doi: 10.1029/2006GL027931.

574 Moore, D. E., Rymer, M.J., 2007. Talc-bearing serpentinite and the creeping section of the San Andreas fault. Nature 448, 795-797. 
576 O'Hara, K. D., Mizoguchi, K., Shimamoto, T., Hower, J., 2006. Experimental frictional

577 heating of coal gouge at seismic slip rates: Evidence for devolatilization and $578 \quad$ thermal pressurization of gouge fluids.Tectonophysics 424, 109-118.

579 Rice, J. R., 2006. Heating and weakening of faults during earthquake slip. J. Geophys. Res. 110, B05311, doi: 10.1029/2005J B004006.

581 Shimamoto, T., Tsutsumi, A., 1994. A new rotary-shear high-speed frictional testing machine: its basic design and scope of research. Structural Geology, The Journal of Tectonic Group Japan 39, 65-78 (in Japanese with English abstract).

584 Sibson, R., 1973. Interactions between temperature and pore-fluid pressure during earthquake faulting and a mechanism for partial or total stress relief. Nature 243, $66-68$.

Spray, J., 1992. A physical basis for the frictional melting of some rock-forming minerals. Tectonophysics 204, 2205-221.

Spray, J., 1993. Viscosity determination of some fractionally generated silicate melts: implication for fault zone rheology at high strain rates. J. Geophys. Res. 98, 8053-8068.

Subarya, C., Chlieh, M., Prawirodirdjo, L., Avouac, J., Bock, Y., Sieh, K., Meltzner, A.J., Natawidjaja, D.H., R. McCaffrey, R., 2006. Plate-boundary deformation associated with the great Sumatra-Andaman earthquake. Nature 440, 46-51.

595 Tibi, R., G. Rock, Estabrook, C.H., 2002. Seismic body wave constraint on mechanisms of intermediate-depth earthquakes. J. Geophys. Res. 107, doi:10.1029/200JB000361.

598 Ulmer, P., Trommsdorff, V., 1995. Serpentine stability to mantle depths and 
$599 \quad$ subduction-related magmatism. Science 268, 858-861.

600 Viti, C., 2010. Serpentine minerals discrimination by thermal analysis. American $601 \quad$ Mineralogist 95, 631-638.

602 Viti, C., Hirose, T., 2010. Thermal decomposition of serpentine during coseismic

603 faulting: Nanostructures and mineral reactions. J. Struct. Geol. 32, 1476-1484.

604 Wibberley, C. A. J., 2007. Seismology: Talc at fault. Nature 448, 756-757.

605 Wibberley, C. A. J., Shimamoto, T., 2005. Earthquake slip weakening and asperities

606 explained by thermal pressurization. Nature 436, 689-692.

607 Yagi, Y., Fukahata, Y., 2011. Rupture process of the 2011 Tohoku-oki earthquake and 608 absolute elastic strain release. Geophys. Res. Lett. 38, L19307, 609 doi:10.1029/2011GL048701.

610 


\section{Captions to figures}

612 Figure 1. Diagram showing the rotary-shear low- to high-velocity frictional testing machine equipped with a hydraulic pressure vessel. 1: specimen holder (one-axis rotary-shear specimen box); 2: pressure vessel for elevated pore-water pressure; 3-4: torque and axial force gauges; 4: electromagnetic clutch; 5: force gouge; 6: oil pressure cylinder; 7: servo-motor and gear system; 8: motor controller; 9: manual pump; 10: oil pressure pump; 11-12: manual oil pressure pump; 13: pressure generator system; 14-15: data recording system. This machine was installed at Shizuoka University, Japan, in early 2007.

623 Figure 3. Petrographic features of serpentinite used for the frictional experiments in this study. (a) Photomicrograph (cross polarized light); (b) scanning electron image. The serpentinite is composed of $65 \%$ serpentine (antigorite) and $35 \%$ olivine.

626 Figure 4. Photographs taken through the transparent window cover of the experimental apparatus showing dust and water vapor (a, c, d), and sparks of yellow-red melt (b) ejected from the interface (slip zone) of two cylindrical serpentinite specimens at a slip rate of $1.10 \mathrm{~m} / \mathrm{s}$ and normal stress of $6.5 \mathrm{MPa}$ during a high-velocity friction (HVF) experiment (HVF R001). The water vapor cooled to form water droplets (Wd) upon the window cover along a zone of 2-7 $\mathrm{mm}$ in width during the $20 \mathrm{sec}$ duration of the experiment.

Figure 5. Photomicrograph (a) and back-scattered electron micrograph (b) showing 
representative microstructures of a simulated fault zone (slip zone) in a high-velocity friction (HVF) experiment (run HVF R001) conducted at a slip rate of $1.10 \mathrm{~m} / \mathrm{s}$. Note that dehydrated zones $(\mathrm{dz})$ are developed on both sides of the slip zone.

Figure 6. Back-scattered electron micrographs showing representative microstructures of a simulated fault zone (slip zone) in experiment run HVF R001 conducted at a slip rate of $1.10 \mathrm{~m} / \mathrm{s}$, showing (a) the slip zone and dehydration zone (dz); (b) a close-up view of the dehydrated zone in serpentine; (c) a close-up view of (b); and (d) representative textures of run products ejected from the slip zone, showing melt textures and flow layers, vesicles (v), and a fine-grained matrix (molten material). showing the textures of vesicles and fine-grained clasts (HVF R001 run product).

648 Figure 8. Powder X-ray diffraction spectra derived from (a) the host serpentinite, (b)

649 reference olivine, and (c-f) representative run products remaining in the slip zone, for experiments with a slip rate of $1.31 \mathrm{~m} / \mathrm{s}$ and normal stress of $5 \mathrm{MPa}$ (run HVF R012) (c), and a slip rate of $1.10 \mathrm{~m} / \mathrm{s}$ and normal stress of $6.5 \mathrm{MPa}$ (run HVF R001) (d). The sample (HVF 012) was picked from the run product material extruded from the slip zone, and the sample (HVF R001) was separated from the run product remained in the slip zone. (e) Enlargement of (d) between $2 \theta$ values of $15^{\circ}$ and $35^{\circ}$, and (f) calibrated sample containing $90 \mathrm{wt} . \%$ fine-grained clasts of run product and 10 wt.\% glass (obsidian). ol: olivine; ant: antigorite. Note that the 
run product (HVF R001) showed a distinct, broad range of $2 \theta$ values from $20^{\circ}$ to $35^{\circ}$, as observed for the calibrated sample containing $10 \mathrm{wt} . \%$ glass (f). The vertical axis (diffraction density) is the same for all spectra. CPS: counts per second.

661

662

663

664

665

666

667

668

669

670

671

672

673

674

675

676

677

678

679

Figure 9. Variation of major oxides in the host serpentinite, slip zone and dehydration zone generated in the HVF experiments. Data are shown in Tables 2-4.

Figure 10. Friction coefficient versus time for experiment run HVF R012 at a slip rate of $1.31 \mathrm{~m} / \mathrm{s}$ and normal stress of $5 \mathrm{MPa}(\mathrm{a}-\mathrm{b})$, and run LVFR1 10 at a slip rate of 0.35 $\mathrm{m} / \mathrm{s}$ and normal stress of $8 \mathrm{MPa}(\mathrm{c}-\mathrm{d})$. (b) Enlargement of the first $2.4 \mathrm{sec}$ of the HVF experiment shown in (a). (d) Enlargement of the first $20 \mathrm{sec}$ of the LVF experiment shown in (c).

Figure 11. Representative FTIR spectra of the host rock (serpentinite) and run product of a high-velocity friction experiment (MH R0012). Note that the $\mathrm{OH}$ peaks are present at $3500-3700 \mathrm{~cm}^{-1}$ in the host serpentine sample but not in the slip zone.

Figure 12. Water contents of the high-velocity friction (HVF) run products calculated from the Fourier transform infrared (FTIR) spectra. Note that the narrow and wide zones reflect a change in slip zone width, as shown in Figs 5 and 6.

Figure 13. Thermogravimetry-differential scanning calorimetry (TG-DSC) spectra of the host rock (serpentinite). (a) TG, (b) DSC. Note that the heat flux during the heating showed an endothermic peak at $550-700^{\circ} \mathrm{C}$ and an exothermic peak at $800-850^{\circ} \mathrm{C}$.

Figure 14. Thermogravimetry-differential scanning calorimetry (TG-DSC) spectra of the run products of high-velocity friction (HVF) experiments (No. 1 and No. 2), 
680 and low-velocity friction (LVF) experiments (MH001 and MH002). (a) TG, (b)

681 DSC. See the text for details.

682 


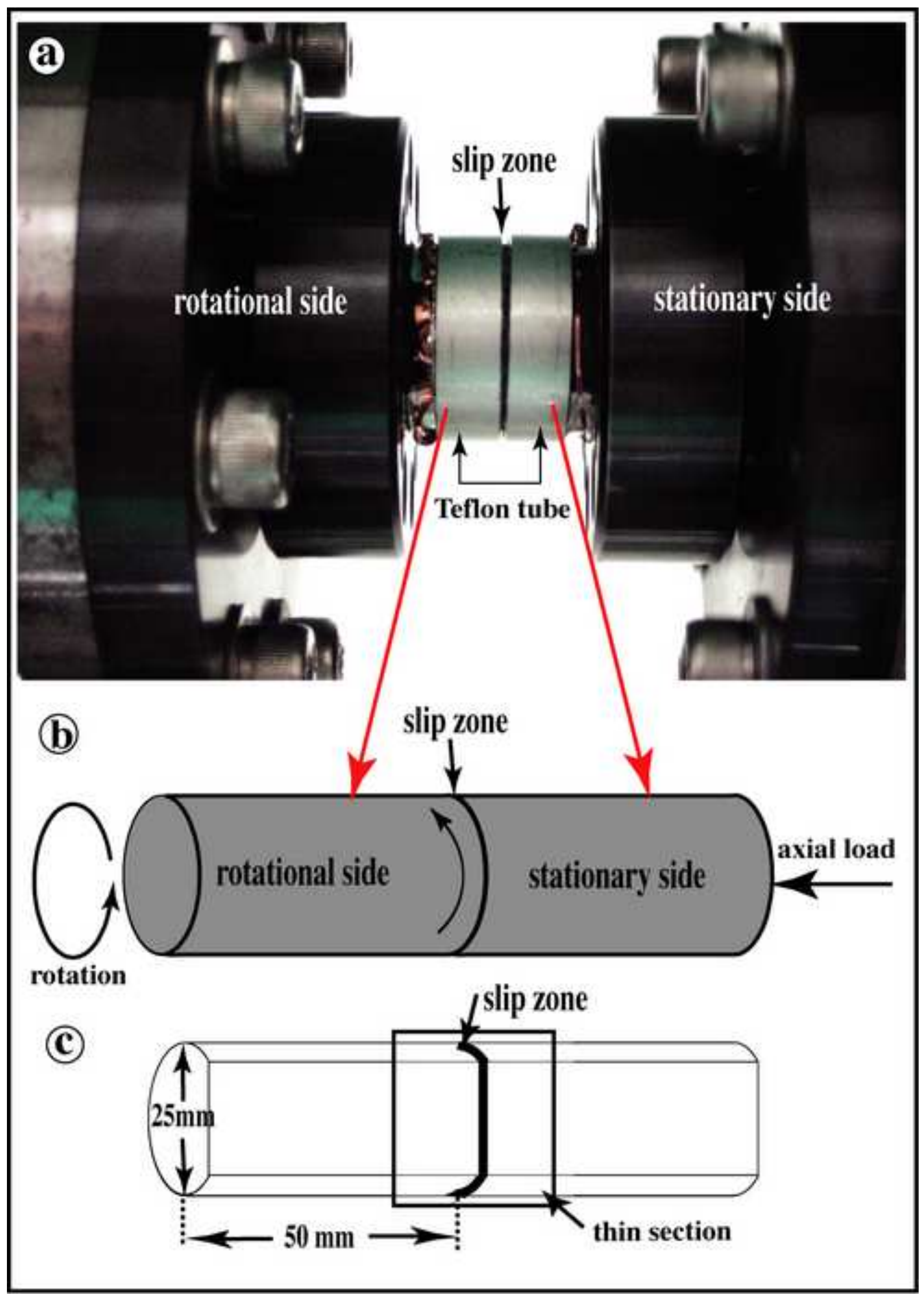


$3 \times-13 \times 2 \%$

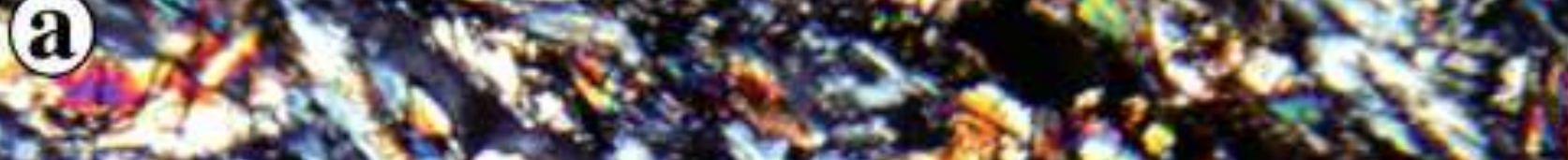

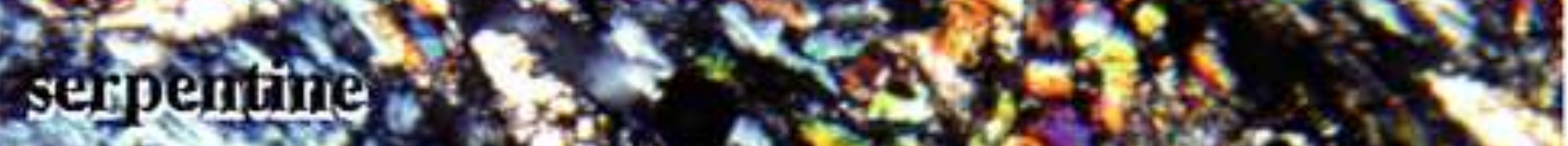

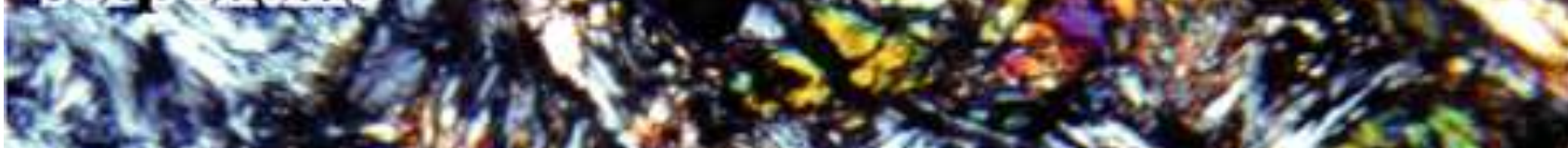
ond 3 y 105 $29 \mathrm{x}$

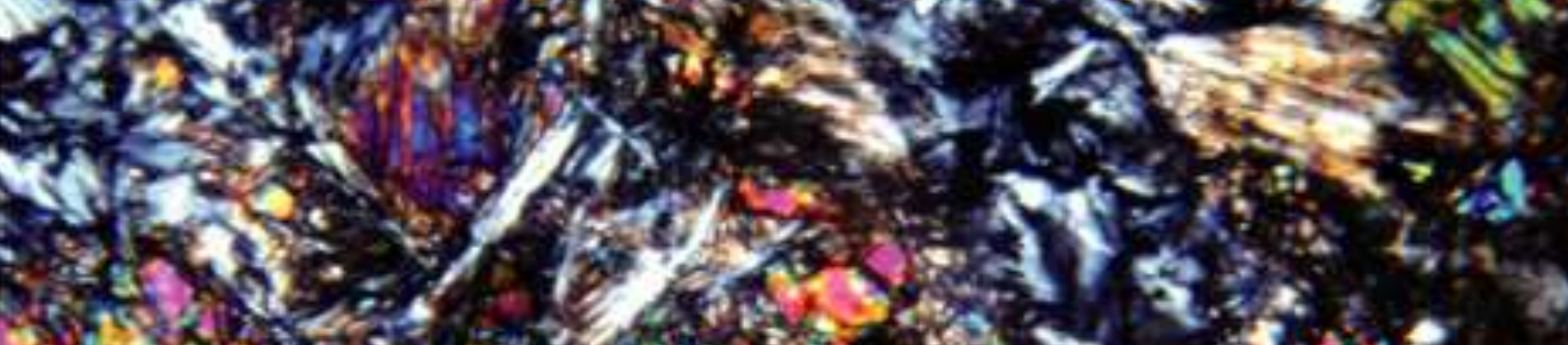

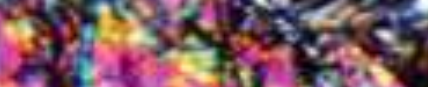
7)

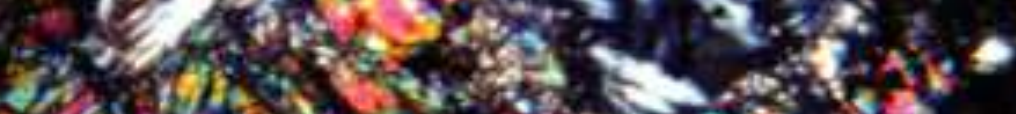

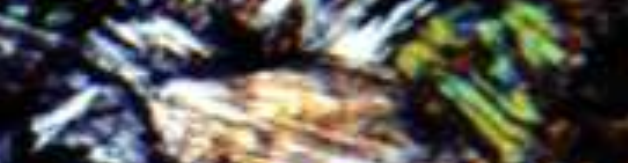
(14) 13 te

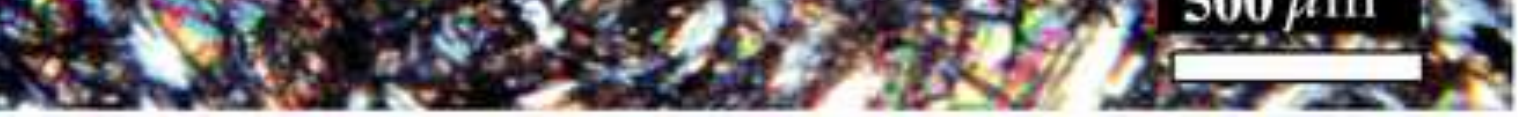

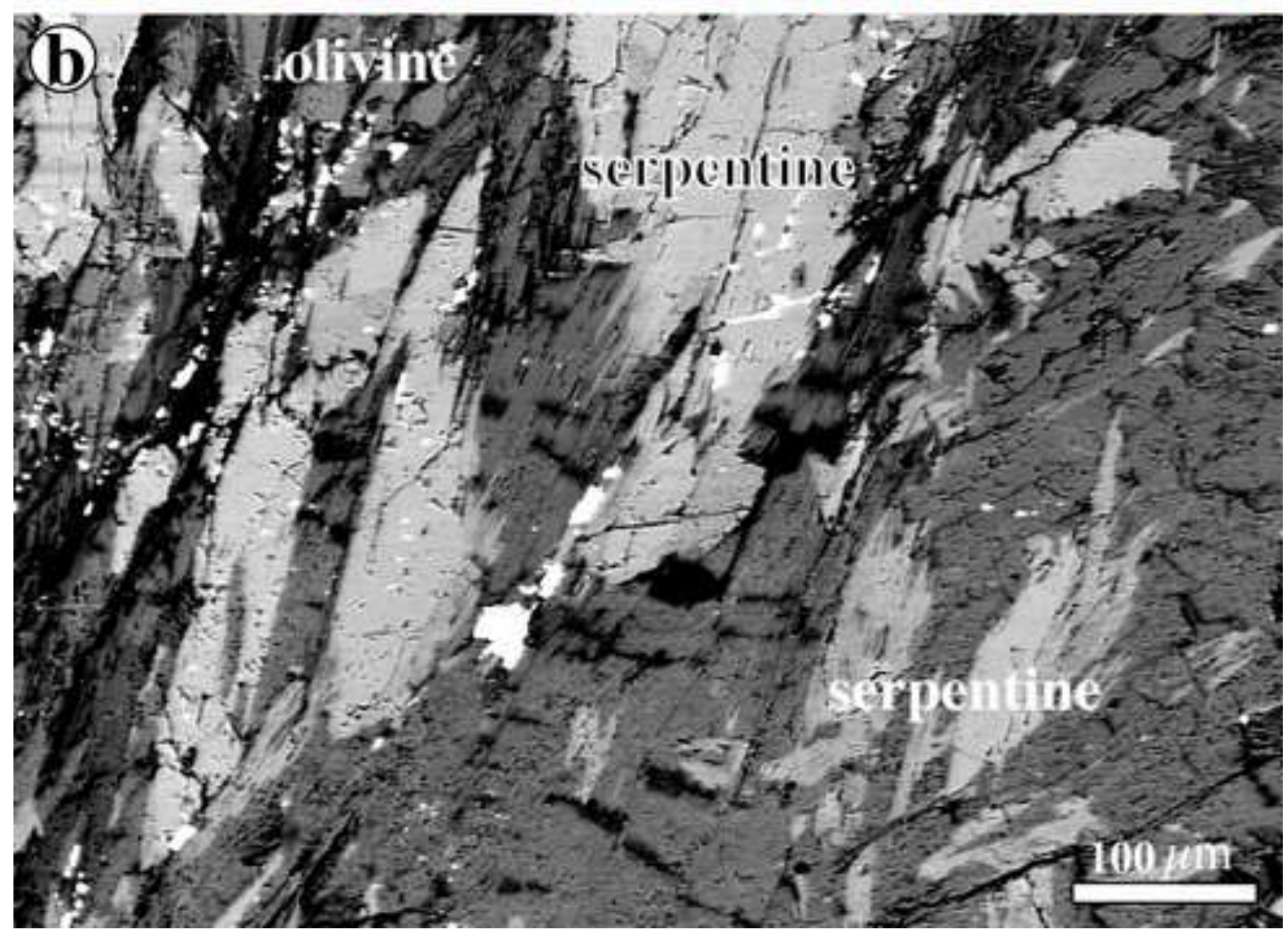



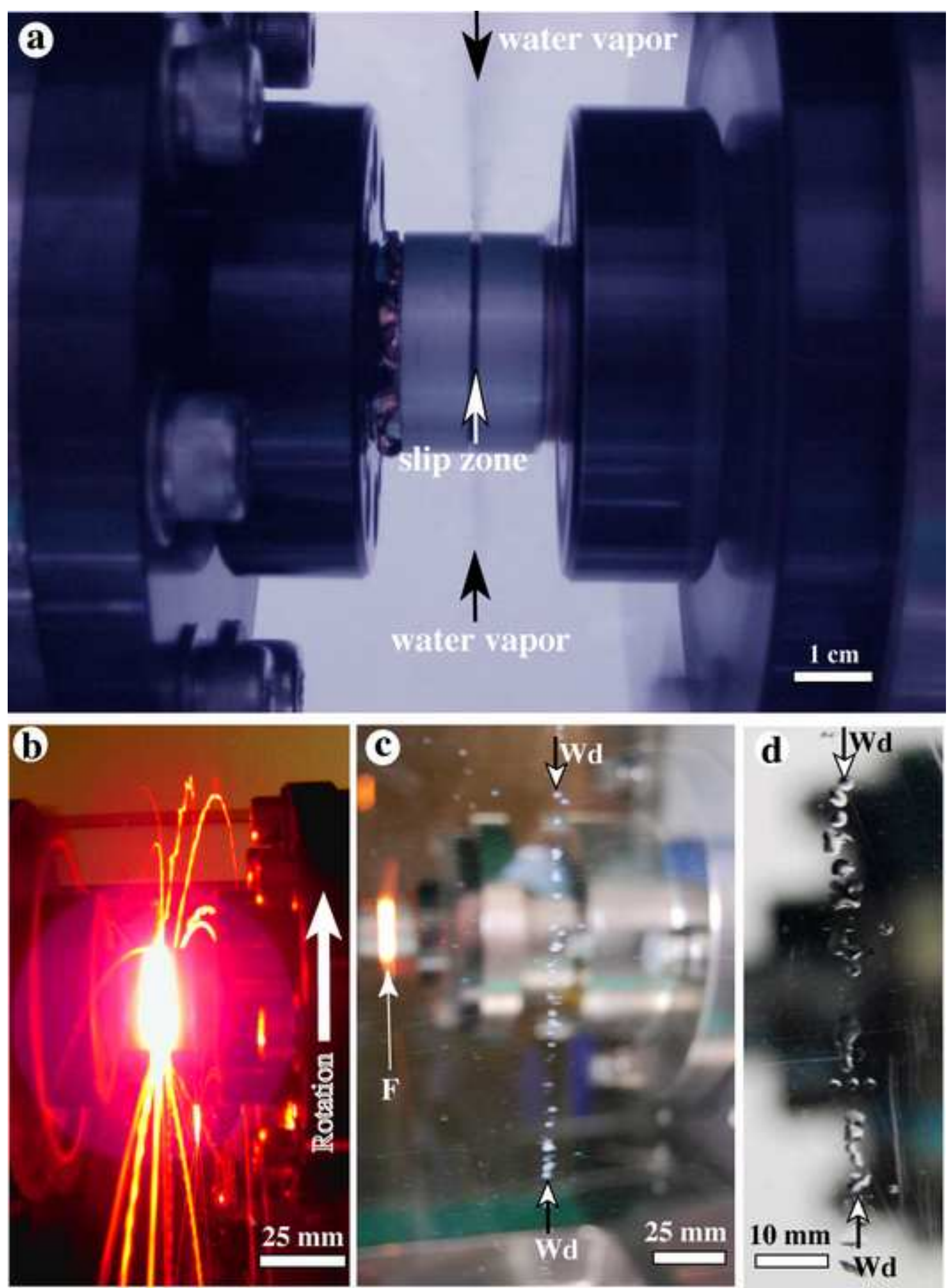

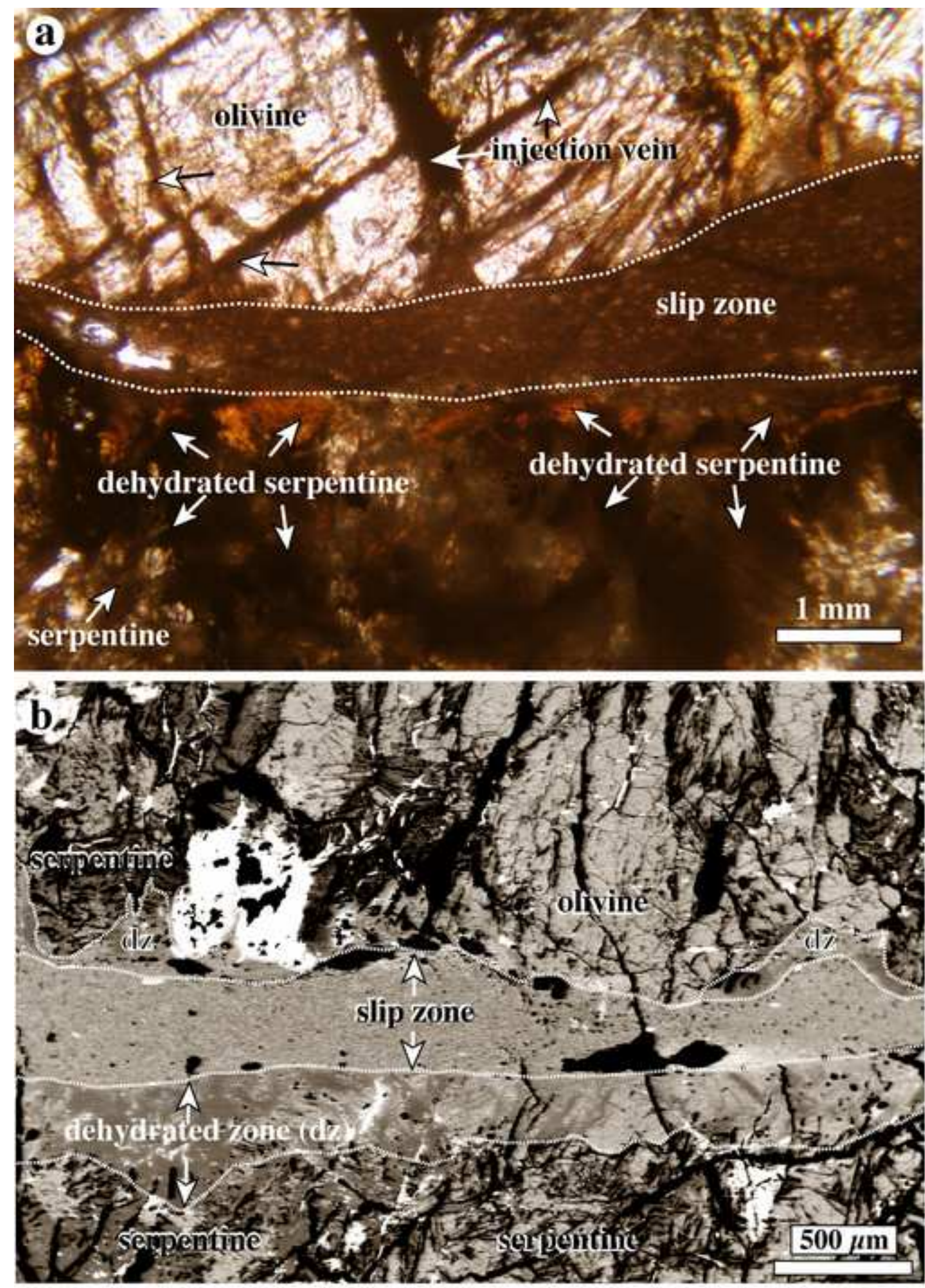
Click here to download high resolution image
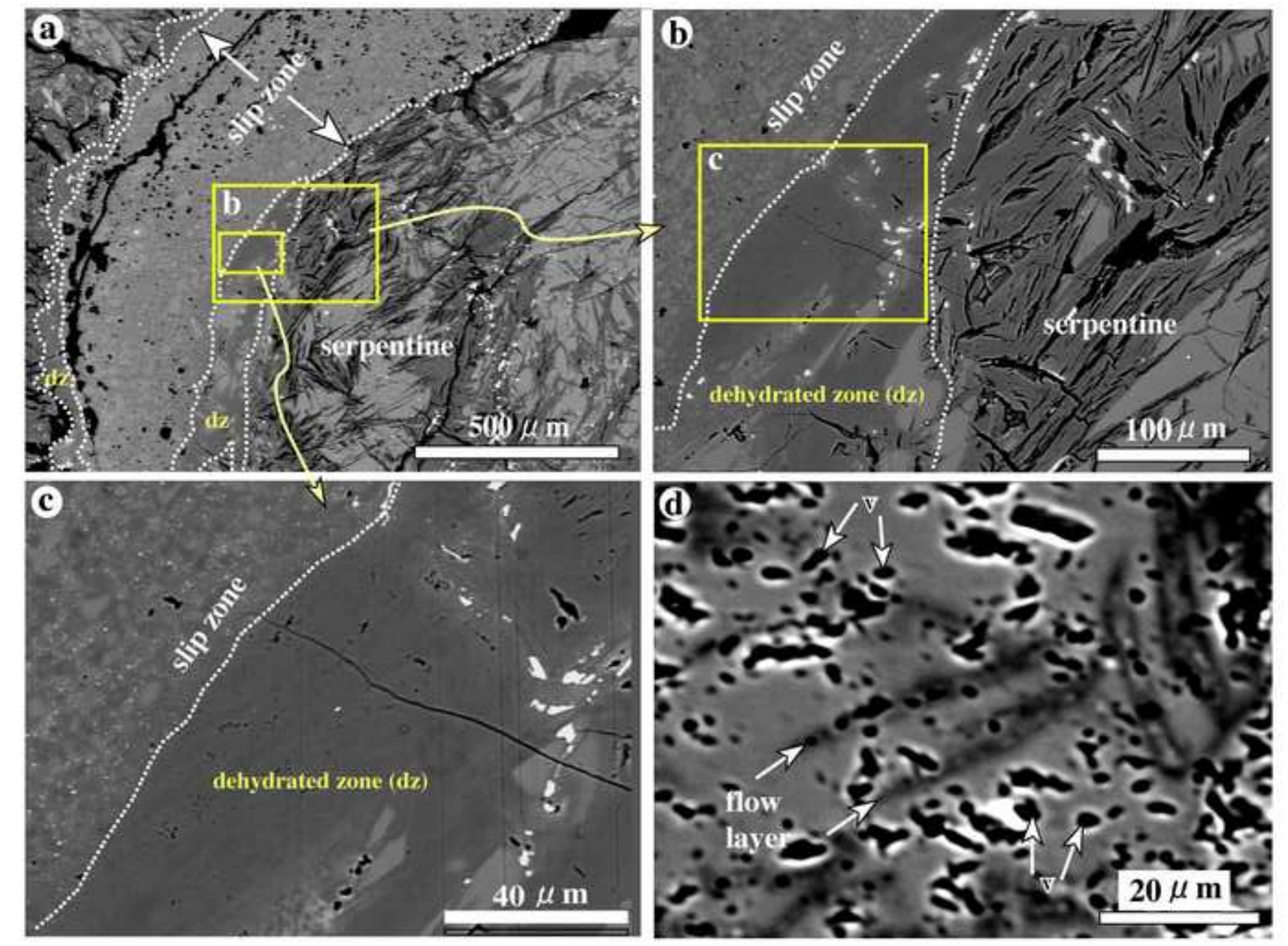


\section{C 都大学}
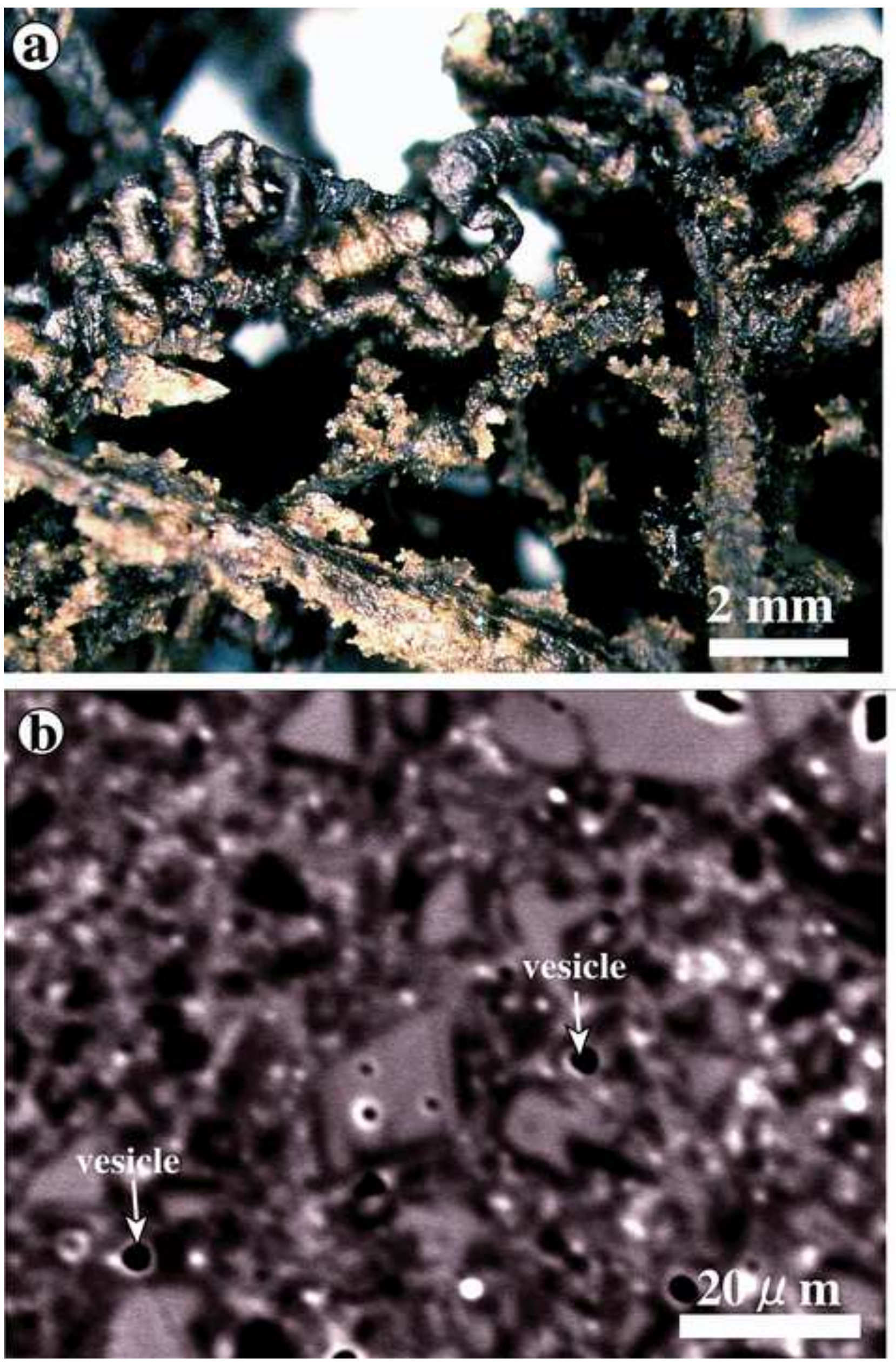


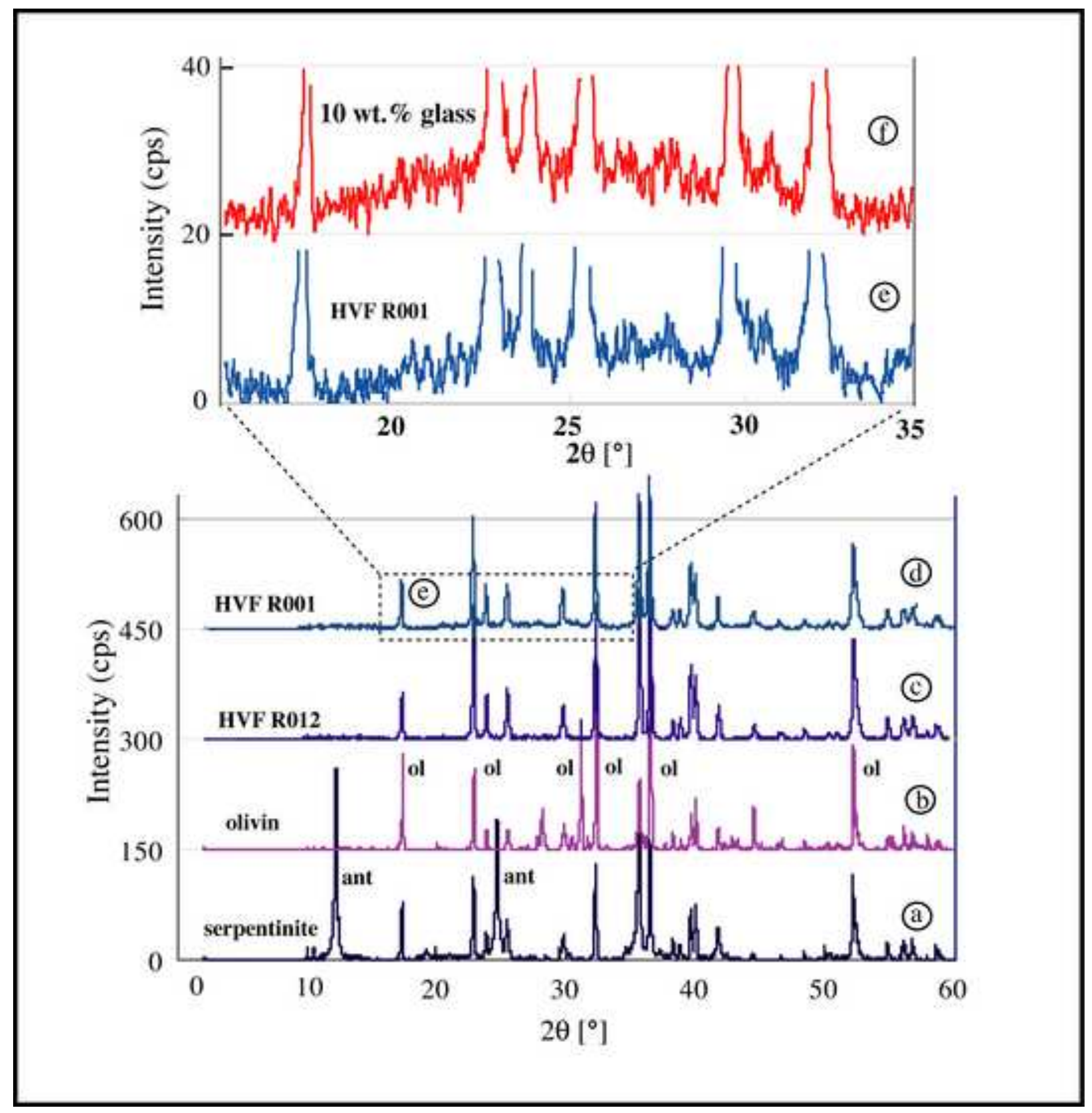



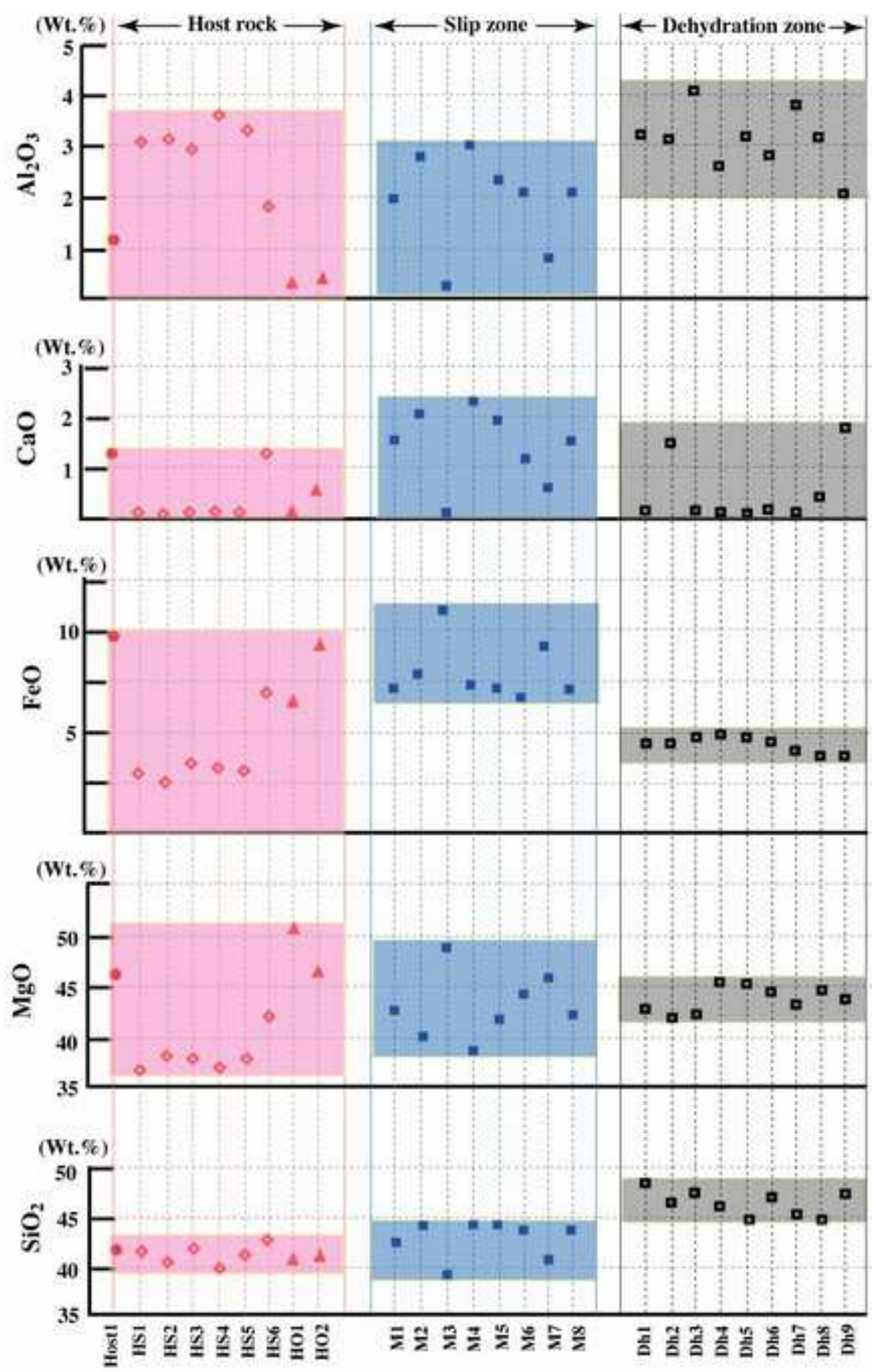

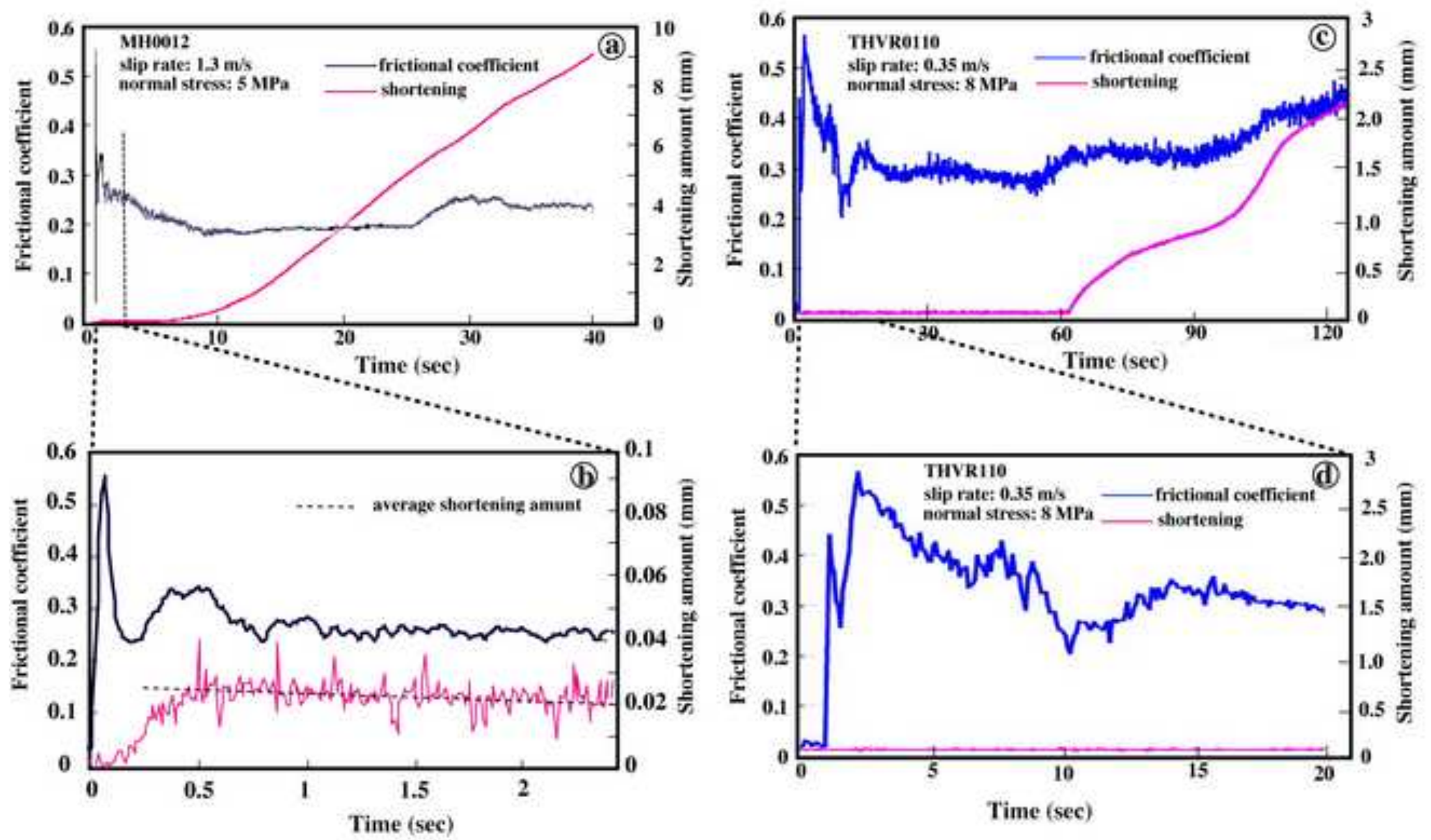


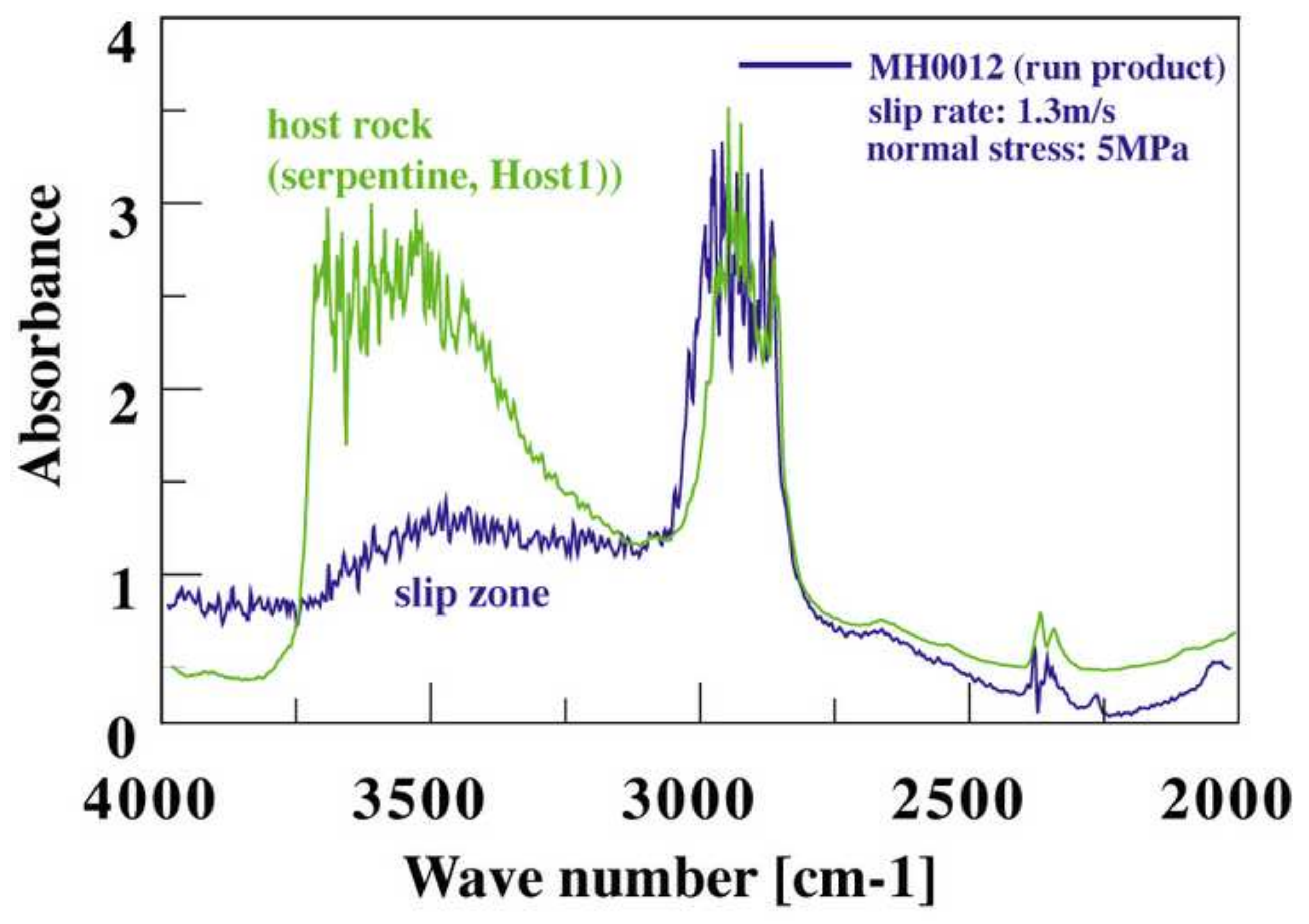




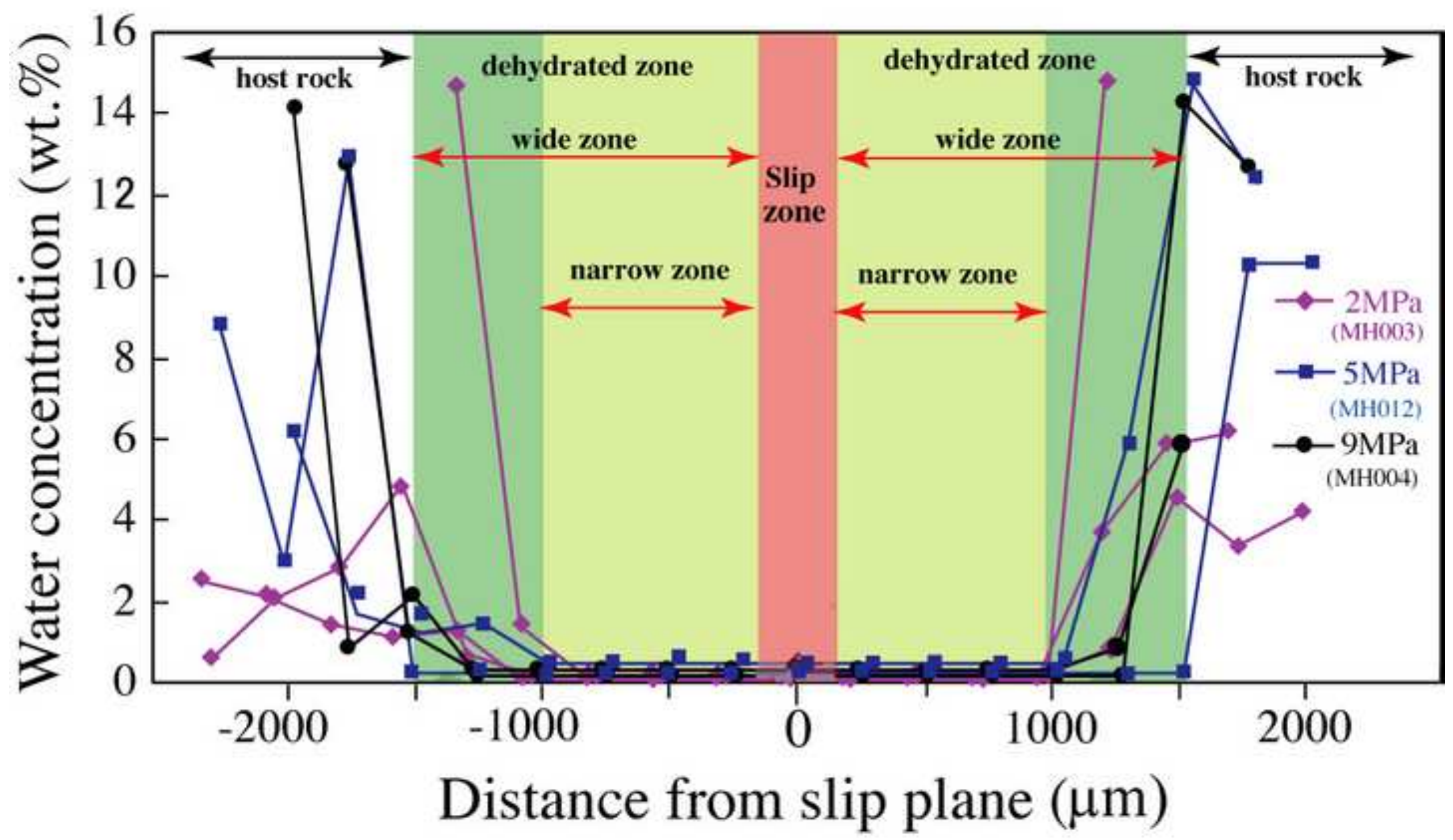



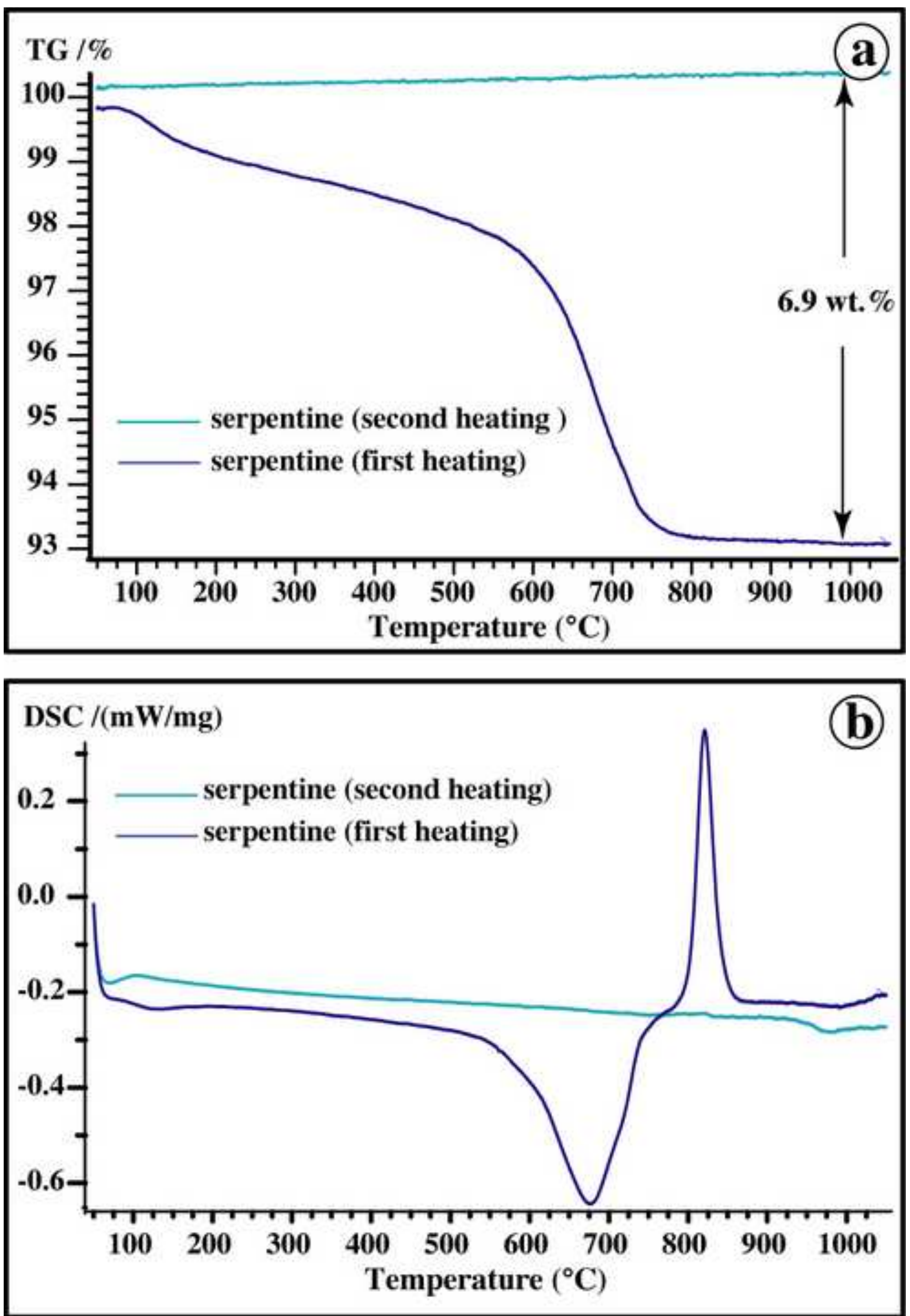

DSC $/(\mathrm{mW} / \mathrm{mg})$ 

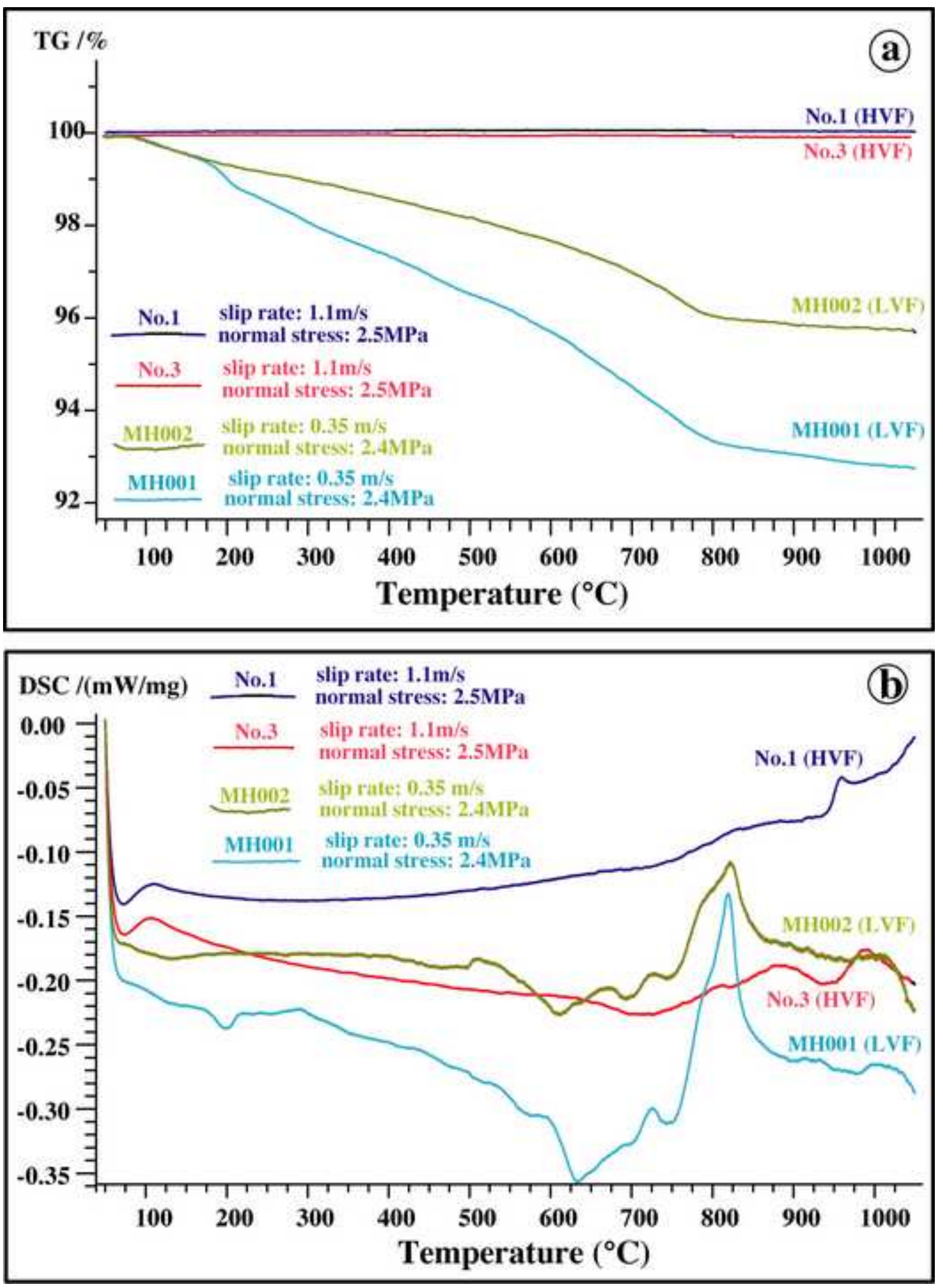
Table 1. Run products used for microscopic analyses.

\begin{tabular}{lccl}
\hline Run number & Normal stress (MPa) & Slip rate $(\mathrm{m} / \mathrm{s})$ & \\
\cline { 2 - 3 } No.1 & 2.5 & 1.10 & Analytical method \\
No.3 & 2.5 & 1.10 & TG-DSC analysis \\
MH001 & 2.4 & 0.35 & TG-DSC analysis \\
MH002 & 2.4 & 0.35 & TG-DSC analysis \\
MH003 & 2 & 1.10 & FTIR analysis \\
MH004 & 9 & 1.10 & FTIR analysis \\
MH012 & 5 & 1.31 & FTIR analysis \\
HVF R001 & 6.5 & 1.10 & Powder X-Ray analysis, EPMA \\
HVF R007 & 4 & 1.31 & Powder X-Ray analysis, EPMA \\
THVR110 & 8.1 & 0.35 & Frictional cofficient, shortening \\
HVF R012 & 5 & 1.31 & Powder X-Ray analysis, EPMA \\
& & & \\
\hline
\end{tabular}


Table 2. Compositions of host rock (Host1, XRF) and serpentine (HS1-HS6, EPMA) and olivine (HO1-HO2, EPMA) materials in the host rock.

\begin{tabular}{lrrrrrrrrr}
\hline $\begin{array}{l}\text { Sample } \\
\text { No. }\end{array}$ & Host1 & HS1 & HS2 & HS3 & HS4 & HS5 & HS6 & HO1 & HO2 \\
\hline $\mathrm{SiO} 2$ & 41.580 & 41.322 & 40.648 & 41.944 & 40.068 & 41.422 & 42.828 & 40.576 & 41.185 \\
$\mathrm{TiO} 2$ & 0.000 & 0.196 & 0.199 & 0.196 & 0.19 & 0.191 & 0.002 & 0.002 & 0.011 \\
$\mathrm{~A} 2 \mathrm{O} 3$ & 1.098 & 3.076 & 3.104 & 2.919 & 3.610 & 3.224 & 1.777 & 0.175 & 0.800 \\
$\mathrm{FeO}$ & 9.904 & 3.063 & 2.887 & 3.674 & 3.268 & 3.225 & 7.074 & 6.327 & 9.335 \\
$\mathrm{MnO}$ & 0.228 & 0.137 & 0.170 & 0.181 & 0.14 & 0.166 & 0.127 & 0.140 & 0.181 \\
$\mathrm{MgO}$ & 45.908 & 36.694 & 38.194 & 37.997 & 37.141 & 38.112 & 43.460 & 51.206 & 46.294 \\
$\mathrm{CaO}$ & 1.242 & 0.106 & 0.114 & 0.106 & 0.095 & 0.088 & 1.260 & 0.127 & 0.526 \\
$\mathrm{Na} 2 \mathrm{O}$ & 0.034 & 0.086 & 0.108 & 0.093 & 0.125 & 0.111 & 0.074 & 0.010 & 0.036 \\
$\mathrm{~K} 2 \mathrm{O}$ & 0.012 & 0.060 & 0.063 & 0.059 & 0.073 & 0.065 & --- & 0.011 & 0.010 \\
$\mathrm{~V}$ & 0.029 & 0.213 & 0.185 & 0.211 & 0.208 & 0.211 & --- & 0.026 & 0.002 \\
$\mathrm{Cr} 2 \mathrm{O} 3$ & --- & 1.284 & 1.089 & 0.593 & 1.026 & 1.098 & 0.509 & 0.103 & 0.153 \\
$\mathrm{NiO}$ & 0.398 & 0.352 & 0.35 & 0.364 & 0.307 & 0.308 & 0.326 & 0.311 & 0.319 \\
\hline Total & 99.973 & 86.588 & 87.11 & 88.337 & 86.249 & 88.219 & 97.438 & 99.013 & 98.852 \\
\hline $\mathrm{X} F:$ & & &
\end{tabular}

XRF: X-ray fluorescence analysis; EPMA: Electron microprobe analysis;

FeO*: all Fe...; -not measured 
Table 3. Chemical compositions of molten materials derived from the slip zone (M1-M8, EPMA).

\begin{tabular}{|c|c|c|c|c|c|c|c|c|}
\hline $\begin{array}{l}\text { Sample } \\
\text { No. }\end{array}$ & M1 & M2 & M3 & M4 & M5 & M6 & M7 & M8 \\
\hline $\mathrm{SiO}_{2}$ & 42.366 & 44.776 & 39.494 & 44.441 & 44.073 & 43.809 & 41.185 & 43.629 \\
\hline $\mathrm{TiO}_{2}$ & 0.015 & 0.012 & 0.001 & 0.025 & 0.022 & 0.003 & 0.011 & 0.000 \\
\hline $\mathrm{Al}_{2} \mathrm{O}_{3}$ & 1.971 & 2.814 & 0.000 & 3.010 & 2.371 & 2.003 & 0.800 & 2.044 \\
\hline $\mathrm{FeO}^{*}$ & 7.144 & 7.860 & 11.243 & 7.465 & 7.289 & 6.704 & 9.335 & 7.391 \\
\hline $\mathrm{MnO}$ & 0.081 & 0.077 & 0.207 & 0.095 & 0.141 & 0.080 & 0.181 & 0.103 \\
\hline $\mathrm{MgO}$ & 43.176 & 40.053 & 48.68 & 38.99 & 42.037 & 44.681 & 46.294 & 42.209 \\
\hline $\mathrm{CaO}$ & 1.595 & 2.020 & 0.014 & 2.275 & 1.953 & 1.138 & 0.526 & 1.422 \\
\hline $\mathrm{Na}_{2} \mathrm{O}$ & 0.126 & 0.126 & 0.003 & 0.159 & 0.139 & 0.097 & 0.036 & 0.076 \\
\hline $\mathrm{K}_{2} \mathrm{O}$ & 0.006 & 0.005 & 0.002 & 0.011 & 0.000 & 0.000 & 0.010 & 0.014 \\
\hline $\mathrm{V}$ & 0.035 & 0.034 & 0.029 & 0.024 & 0.003 & 0.022 & 0.002 & 0.015 \\
\hline $\mathrm{Cr}_{2} \mathrm{O}_{3}$ & 0.324 & 0.403 & 0.000 & 0.537 & 0.650 & 0.655 & 0.153 & 0.459 \\
\hline $\mathrm{NiO}$ & 0.350 & 0.284 & 0.398 & 0.295 & 0.228 & 0.254 & 0.319 & 0.292 \\
\hline Total & 97.188 & 98.464 & 99.558 & 97.328 & 98.908 & 99.446 & 98.852 & 97.654 \\
\hline
\end{tabular}

EPMA: Electron microprobe analysis;

$\mathrm{FeO}^{*}$ : all $\mathrm{Fe}$ 
Table 4. Chemical compositions of serpentine minerals in the dehydration zones (Dh1-Dh9, EPMA).

\begin{tabular}{lccrrrrrrr}
\hline Sample & & & & & & & & & \\
No. & Dh1 & Dh2 & Dh3 & Dh4 & Dh5 & Dh6 & Dh7 & Dh8 & Dh9 \\
\hline $\mathrm{SiO} 2$ & 47.462 & 45.76 & 46.881 & 45.543 & 44.184 & 46.035 & 44.832 & 44.243 & 46.742 \\
$\mathrm{TiO} 2$ & 0.000 & 0.011 & 0.025 & 0.000 & 0.013 & 0.000 & 0.005 & 0.003 & 0.000 \\
$\mathrm{Al2O} 3$ & 3.198 & 3.107 & 4.020 & 2.549 & 3.123 & 2.768 & 3.813 & 3.116 & 1.998 \\
$\mathrm{FeO} *$ & 4.023 & 4.245 & 4.482 & 4.225 & 4.059 & 3.978 & 4.016 & 3.826 & 3.794 \\
$\mathrm{MnO}$ & 0.031 & 0.054 & 0.031 & 0.035 & 0.012 & 0.031 & 0.030 & 0.050 & 0.027 \\
$\mathrm{MgO}$ & 43.347 & 42.058 & 42.198 & 45.431 & 45.116 & 44.074 & 43.134 & 44.208 & 43.458 \\
$\mathrm{CaO}$ & 0.249 & 1.424 & 0.056 & 0.027 & 0.018 & 0.015 & 0.048 & 0.398 & 1.797 \\
$\mathrm{Na} 2 \mathrm{O}$ & 0.033 & 0.054 & 0.041 & 0.028 & 0.028 & 0.024 & 0.063 & 0.113 & 0.121 \\
$\mathrm{~K} 2 \mathrm{O}$ & 0.000 & 0.010 & 0.004 & 0.000 & 0.012 & 0.002 & 0.001 & 0.005 & 0.013 \\
$\mathrm{~V}$ & 0.024 & 0.020 & 0.034 & 0.018 & 0.025 & 0.018 & 0.040 & 0.030 & 0.001 \\
$\mathrm{Cr} 2 \mathrm{O} 3$ & 0.419 & 0.236 & 0.870 & 0.463 & 0.889 & 0.476 & 1.441 & 1.605 & 0.621 \\
$\mathrm{NiO}$ & 0.151 & 0.160 & 0.134 & 0.181 & 0.214 & 0.165 & 0.223 & 0.157 & 0.163 \\
\hline & & & & & & & & & \\
Total & 98.936 & 97.139 & 98.777 & 98.500 & 97.693 & 97.586 & 97.646 & 97.755 & 98.735 \\
\hline
\end{tabular}

EPMA: Electron microprobe analysis;

FeO*: all Fe 